\title{
?1
}

TI 2020-021/V

Tinbergen Institute Discussion Paper

\section{How Costly is using Livestock as a Saving Device? A Note on Meat Prices during Food Shortages}

Revision: March 2022

Wouter Zant ${ }^{1}$ 
Tinbergen Institute is the graduate school and research institute in economics of Erasmus University Rotterdam, the University of Amsterdam and Vrije Universiteit Amsterdam.

Contact: discussionpapers@tinbergen.nl

More TI discussion papers can be downloaded at https://www.tinbergen.nl

Tinbergen Institute has two locations:

Tinbergen Institute Amsterdam

Gustav Mahlerplein 117

1082 MS Amsterdam

The Netherlands

Tel.: + 31(0)205984580

Tinbergen Institute Rotterdam

Burg. Oudlaan 50

3062 PA Rotterdam

The Netherlands

Tel.: +31(0)10408 8900 


\section{How Costly is using Livestock as a Savings Device?}

\section{A Note on Meat Prices during Food Shortages}

by Wouter Zant

\section{Abstract}

We measure to what extent the value of livestock is reduced during food shortages. For this purpose we exploit Malawian monthly market prices of meat and maize - the major staple food in Malawi - for 72 locations (towns, villages and markets) from January 1991 to December 2009. We show that drops in the meat-maize terms of trade are associated with food shortages and decreases during food shortages in local markets with $27 \%$ to $85 \%$. The evidence is consistent with increased livestock sales during food shortages, but the drop in meat-maize terms of trade arises primarily due to increases of maize prices. Our results are robust to spatial correlation and various other threats. Similar drops in livestock value are shown to occur in other SSA countries. The drop in meat-maize terms of trade reduces the value of livestock - a major savings device in SSA countries - at the very moment livestock is sold on the market to purchase staple foods. Like produced staple foods, agricultural households systematically sell low. To bridge food shortage periods savings instruments are needed that do not lose value when liquidated. A few policy options are discussed. Grain storage at the household level appears most promising.

JEL code: O16, D19, Q13, R12, O55

Key words: food security, saving, drought, livestock, subsistence farming, storage, Malawi, Africa

* Wouter Zant is associate professor at the Vrije Universiteit and research fellow of the Tinbergen Institute, both Amsterdam, the Netherlands; mailing address: Wouter Zant, Vrije Universiteit, De Boelelaan 1105, room 10A-79, 1081 HV Amsterdam, The Netherlands; email: wouter.zant@vu.nl; tel: +31 205989592 . I am grateful to Erik Koomen for constructing a map of Malawi. This paper greatly improved by suggestions and comments from Christopher Gilbert. All errors are my own. 


\section{Introduction}

In many sub-Saharan countries farm households protect themselves against crop failure by saving through livestock. The objective of the current paper is to measure the size of the reduction of the value of livestock during periods of food shortage and associated with increased sales of livestock and increased market prices of staple foods. On the basis of these measurements we discuss the welfare implications of using livestock as a savings device and lessons for potential alternative saving instruments to overcome periods of food shortage.

The literature on saving and risk is huge. Since our investigations are primarily empirical, we discuss a selected number of articles that focus particularly on the role of livestock for poor rural households in developing countries, rather than aim at an exhaustive review of the literature on saving strategies. The key objectives of work in this area is to identify livestock as a major device for precautionary saving (Kinsey et al.,1998; Turner and Williams, 2002; Mogues, 2011; Hänke and Barkmann, 2017), to show that livestock sales are a primarily used to fund food purchases during food shortages (Kinsey et al.,1998; Turner and Williams, 2002; Mogues, 2011; Hänke and Barkmann, 2017), to assess the extent to which livestock savings are effective in establishing food security at the household level (Kinsey et al.,1998; Fafchamps et al.,1998; Kazianga and Udry, 2006; Hänke and Barkmann, 2017) and to what extent livestock sales are useful in smoothing consumption (Fafchamps et al.,1998; Kazianga and Udry, 2006).

Livestock sales occur often, and often exclusively, during food shortages (Turner and Williams, 2002; Hänke and Barkmann, 2017). More than two third of livestock sales in Niger are made to purchase food, under conditions with a high degree of urgency (Turner and Williams, 2002). Around $50 \%$ of sales of zebu and close to $80 \%$ of the sales of goats in semi-arid south-western Madagascar are driven by food shortages, while during crop failures on average $56 \%$ of food 
expenditures are funded with livestock sales (Hänke and Barkmann, 2017). Some authors find substantial and large contributions of livestock sales (Kinsey et al., 1998; Mogues, 2011). Livestock sales are the major resource that households use to fund food purchases during droughts in Zimbabwe (between $40 \%$ and 50\%), a strategy followed by almost two-third of all households (Kinsey et al., 1998). Weather shocks in Ethiopia lead to asset drawdown by households and this is more pronounced for covariant than for idiosyncratic shocks. Precautionary motives of wealth holding are claimed to be more prevalent for liquid assets and for less productive forms of wealth, hence, larger for grain stocks than for livestock, and larger for small livestock than for large livestock (Kazianga and Udry, 2006; Mogues, 2011). Some authors are less confident about the effectiveness of livestock savings to protect against food shortages. Fafchamps et al. (1998) find that livestock transactions in Burkina Faso compensate for at most $30 \%$, and probably close to $15 \%$ of income shortfalls due to village level shocks alone. Kazianga and Udry (2006) show that fluctuations in household consumption closely track fluctuations in household income associated with drought and subsequent recovery, and find no evidence that livestock sales or financial markets serve as an effective coping strategy against these income fluctuations.

In a useful survey on income risk and coping strategies Dercon (2002) highlights a major drawback of (assets like) livestock when used as a savings device: “.... A(nother) problem with holding assets to buffer consumption is that the terms of trade between goods for consumption and assets change as a result of a common shock. If a negative common shock occurs, households would like to sell some of their assets. However, if everyone wants to sell assets at the same time, asset prices will collapse and the amount of consumption that can be purchased will fall'. The empirical work reported in the current paper aims to quantify the size of the fall in asset prices during food shortages. 
Most work on the impact of livestock sales during food shortages takes the household as the unit of research. This approach has a lot to recommend itself as the key objective is to assess the degree of food security, the degree to which households are capable of buffering fluctuations in income with savings like livestock and to preserve required levels of nutrition. We follow a different route in the current work. Instead of taking the household perspective, we look at markets ${ }^{1}$. We evaluate to what extent food shortages through their impact on market prices affect the value of livestock. Looking at markets rather than at households allows to assess the interaction between meat prices, staple food prices, and sales of livestock during food shortages at the level of the local market, and how these circumstances affect the value of livestock. Households make their decisions in the context of the market, taking prices as given. Food shortages affect large numbers of households simultaneously and so many households will make similar decisions, and market prices adjust accordingly. Availability of a large number of systematically recorded administrative monthly price data, covering an extensive number of geographical locations and a long period with several food shortages, makes this evidence an informative and indispensable complement to household survey based research.

In the remainder of this paper we supply, in Section 1, background information on Malawi. In Section 2 we propose a simple conceptual framework and we elaborate the empirical strategy. In Section 3 we show and discuss estimation results and robustness checks. In Section 4 we assess the implications of the estimation results, and in Section 5 we give a summary and conclusion.

\footnotetext{
${ }^{1}$ Consequently, we can only highlight the market impacts on households, rather than making claims from the household perspective. However, under a number of assumptions we are able to outline the position of a typical household during a food shortage (see Discussion and implications of outcomes).
} 


\section{Livestock, staple food and food shortages in Malawi}

Malawi is a landlocked country in the south of Africa, between $-9.4^{\circ}$ and $-17.1^{\circ}$ latitude and $32.7^{\circ}$ and $35.9^{\circ}$ longitude, around $800 \mathrm{~km}$ from north to south, and around $150 \mathrm{~km}$ from east to west, bordering Zambia, Tanzania and Mozambique ${ }^{2}$. A large lake, Lake Malawi, part of the Great Rift Valley, stretches from north to south, along the eastern border of the country. The Malawian population, which increased during the study period (1991-2009) from close to 9 million to 13-14 million, is mostly rural: only a small fraction ( $11 \%$ to $15 \%)$ lives in the cities Lilongwe, Blantyre, Mzuzu and Zomba. Per capita GDP, expressed in purchasing power parity US\$, in 2009 is between 840 and 900 US\$, making Malawi one of the poorest countries in the world, with a ranking in the bottom 14 of all countries ${ }^{3}$. More than $80 \%$ of the Malawi population depends for food and income on subsistence farming. The incidence of poverty is high: more than $50 \%$ of the population in Malawi is poor (various Integrated Household Surveys) and poverty is extremely high in remote rural districts (e.g. Chitipa in the north: 67.2\%; Nsanje and Chikwawa in the south: respectively $76.0 \%$ and $65.8 \%$, Integrated Household Survey 2004/2005). In the southern region poverty is at least $10 \%$-points higher relative to the central regions.

The key food crop in Malawi is maize. Cassava and rice have very modest market shares that are nevertheless increasing, and are important in a few districts (cassava in Nkhatabay and Nkhotakota, and rice in Karonga and Machinga). Other popular food crops are groundnuts and beans. Tobacco is by far the most important cash crop. Just like the other major cash crops, sugar and tea, tobacco cultivation dates back to the colonial period. Tobacco, however, has become nearly completely smallholder based in the course of the 1990s (Zant, 2020), while tea and sugar

\footnotetext{
${ }^{2}$ A map of Malawi is included in the Appendix (Figure A3).

${ }^{3}$ Per capita GDP of Malawi in US\$ purchasing power parity according to IMF, 2009: 881 US\$ (rank: 170 in a total of 181 countries), according to the World Bank, 2008: 837 US\$ (rank: 156 in a total of 166 countries) and according to CIA, 2009: 900 US\$ (rank: 180 in a total of 193 countries).
} 
are still mainly produced on estates. Nearly every city, town or larger village has one or more markets for agricultural food crops on a regular basis, often daily or weekly: the market price data that we use in the empirical estimations are from 72 markets spread across the entire country ${ }^{4}$.

Maize in Malawi dominates both production and consumption of households. Maize is the major staple food in Malawi, accounting for $52 \%$ to $65 \%$ of the total per capita calorie intake (FAO, 1990, 2002). Due to high population density the largest market for maize is the southern part of the country. Also, nearly all households grow maize. Production of maize in Malawi is undertaken by households primarily for home consumption. As a consequence the quantity of marketed maize is limited: estimates of the marketed share of production range from $5 \%$ to $25 \%$ of domestic production (Jayne et al., 2008). The main maize crop in Malawi is planted from September to November and harvested from March to May. Agriculture in Malawi is rain-fed and rainfall risk is by far the dominant production risk in agriculture (Giné et al., 2009; Ahmed et al., 2020). Variation in rainfall and occasional droughts cause large fluctuations in production of maize. Apart from a distinct geographical variation, especially 1991/92 shows up as a year with an extreme drought, almost throughout Malawi (Table A1). Major crop failures with spatially varying intensity occurred in the crop seasons 1991/92, 1996/97, 2000/2002 and 2004/20055. Periods with food shortages are identified by extremely high staple food prices, in particular maize prices (Figures A2) ${ }^{6}$. Just like prices of all agricultural products and common for sub-Sahara agriculture (Kaminski et al., 2016; Gilbert et al., 2017), Malawi maize prices follow a distinct seasonal pattern, with highs at the end of the marketing season, just before harvesting from January to March, and lows after harvesting from May to July. Within season price differences are large:

\footnotetext{
${ }^{4}$ A map of Malawi in the Appendix (Figure A3) shows the locations of these 72 markets.

${ }^{5}$ Note that the associated food shortage occurs in the marketing year following the year of the crop failure.

${ }^{6}$ However, this does not apply to the large staple food price increases in 2008 which were caused by other factors.
} 
median within season returns for maize are well above $100 \%$. The first months of the calendar year, January to March, are the months where food shortages usually become apparent: during these months the highest maize prices are realized, and we also expect most extra livestock supply on the market, and thereby the lowest meat prices. This correspondence - large increases of maize prices jointly with modest, well below average increases or even decreases in meat prices - is clearly visible in the graphical evidence and seems to support increased supply of livestock during food shortages (Figure 1).

\section{Figure 1 Maize and meat price increases, January to March}

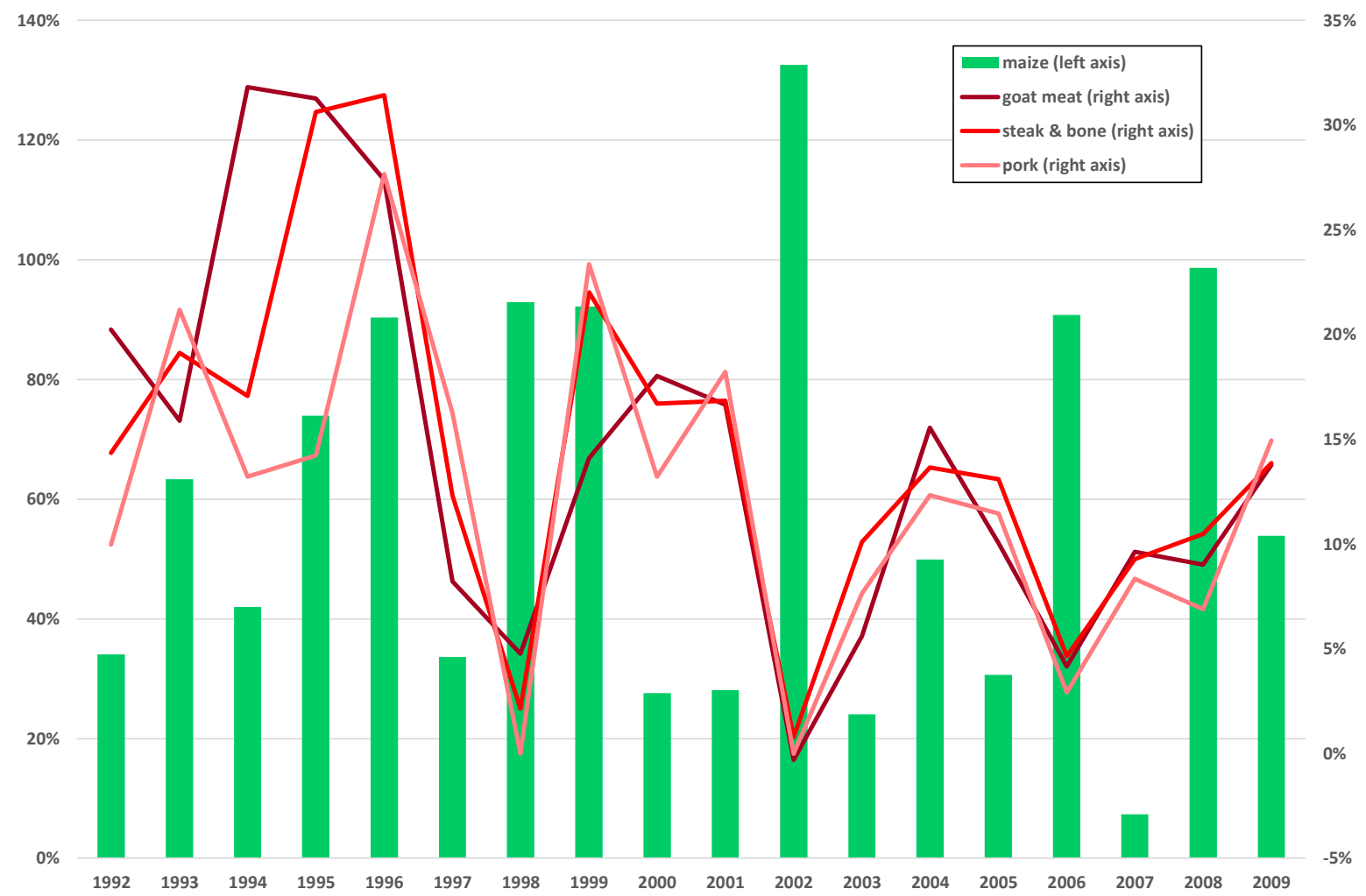

Note: The figures report the average price in January, February and March in a specific year, relative to the average price of the lowest three prices from May to November of the previous year, by each market, and averaged over markets. Source: calculations based on Agro-Economic Survey, Ministry of Agriculture and Food Security, Government of Malawi.

There is no systematic information on livestock dynamics and on livestock transactions at the household level. From this perspective, meat prices by month, for a substantial number of 
markets and for nearly two decades, are therefore the most comprehensive, systematic, frequent and granular source of information. There is, nevertheless, a census among farmers including a module on livestock and various other details (National Census of Agriculture and Livestock (NACAL), Malawi, 2006/2007. The key data document aggregate livestock and aggregate meat over the years ${ }^{7}$. To investigate if these data can be reconciled with household data, we have used the Core Welfare Indicators Questionnaire 2002 (CWIQ2002) which contains similar information on livestock and the livestock module of the Integrated Household Survey 2 (IHS2), with data for the season 2004-2005. Matching the livestock census data (NACAL) with the household survey data (IHS2 and CWIQ2002) yields insight into the averages according to the different sources $^{8}$. We focus on the major types of livestock: cattle, goats, (sheep) and pigs ${ }^{9}$. To make meaningful claims about total livestock rearing, the different types of livestock are converted into tropical livestock units (FAO, 2011, Guidelines for the preparation of livestock sector reviews, 5, Rome). The comparisons of census based data and household based data indicate that the data from different sources are reasonably close to each other (with the possible exception of less populated areas), which gives confidence about their reliability.

On the basis of these data, we find that livestock rearing per household especially takes place in the northern and southern districts. The share of cattle per household in total livestock is clearly the most important type of livestock, however with distinct regional variation: in the outer

\footnotetext{
${ }^{7}$ The key data of the livestock census are available on an annual basis from 2000-2001 onwards (see also appendix).

${ }^{8}$ Averages in the household survey data are conditioned on non-zero livestock in 2004-2005. The share of households with zero livestock at ADD level varies from 1 to $19 \%$, and averages $10 \%$.

${ }^{9}$ In numbers chicken are most prevalent, also in the spread over households, but their contribution to total livestock per household is limited. Also, and unlike the other major types of livestock, we lack data of Malawi market prices for chicken. Chicken are particularly popular because less lumpy and less valuable, and therefore requiring less savings; more flexible in use, both for selling or for own consumption; and having a short reproduction time. A major reason for limited access to livestock savings is asset lumpiness (Dercon, 2002). Note, however, that the larger part of household livestock herds is obtained by reproduction (rather than purchase).
} 
north and outer south (ADDs Karonga, Mzuzu and Shire Valley) cattle covers $65 \%$ to $84 \%$ of total livestock (see appendix). In the central and urban part of the country (ADDs Lilongwe, Blantyre, Salima, Machinga) the smaller types of livestock (goats, sheep and pigs) are more prevalent, covering $49 \%$ to $79 \%$ of total livestock (see appendix). Unfortunately, the core NACAL data on livestock and meat production, available annually from 2000-2001 onwards, did not allow meaningful observations about livestock and meat dynamics ${ }^{10}$.

Figure 2 Tropical livestock units: average number per household by ADD

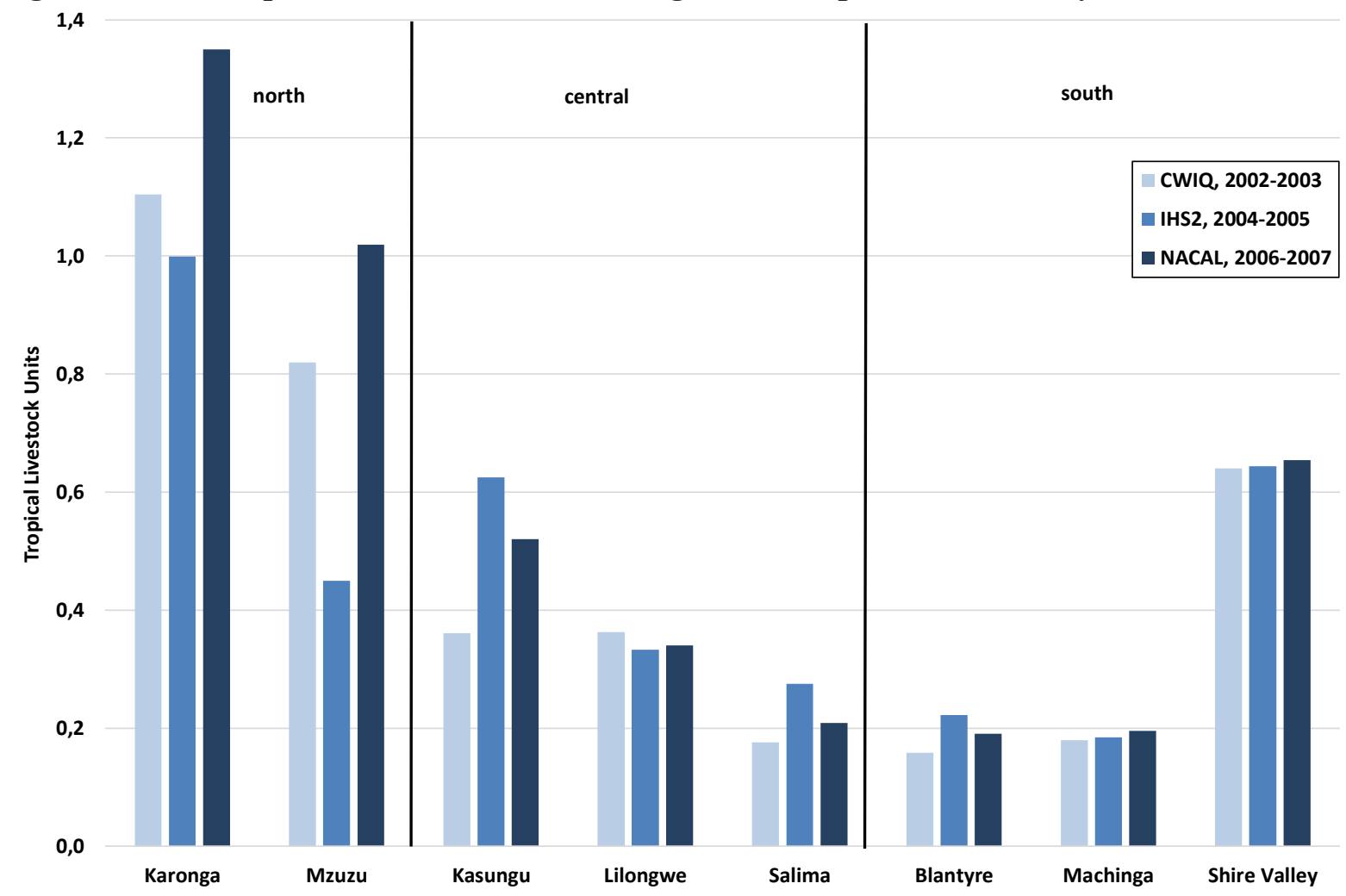

Note to Figure: Conversion weights for tropical livestock units: cattle 0.5 ; goats 0.1 ; pig 0.2 ; sheep 0.1 ; chicken = 0.01 . The average number of livestock per household is conditioned on non-zero livestock in the household. The share of zero livestock in the household at ADD level varies from 1 to $19 \%$, and averages $10 \%$. Source: calculations based on NACAL, Malawi, 2006/2007; CWIQ2002 and Integrated Household Survey 2 (IHS2).

\footnotetext{
${ }^{10}$ For example, reduced livestock and / or increased meat production in food shortage years could not be confirmed with these data. This makes us suspicious about the accuracy of the NACAL data and the way they are compiled.
} 
The size of livestock per household in the central ADDs (Lilongwe, Blantyre, Salima, Machinga) is low (compare, for example, Kinsey et al. 1998): it is difficult to attribute a serious role for livestock in terms of precautionary saving in these areas. Households in the outer north and outer south (Karonga, Mzuzu and Shire Valley) have larger herds of livestock, and may resort (more) to livestock savings because they have fewer alternative options to protect against crop failures. Conversely, households in the central ADDs, where the Malawian cities are located, have easier access to temporary urban wage jobs and other non-farm employment opportunities - a common technique to deal with income shortfalls arising from crop failure or drought - and easier access to food-aid in case emergency arises. Dercon $(1998,2002)$ also indicates off-farm activities as a rational choice for low-income households in case of credit constraints and agricultural risk. Finally, the correspondence between the regional pattern of poverty incidence and the per household number of livestock units is striking ${ }^{11}$.

\section{Conceptual framework, empirical strategy and data}

\section{Conceptual framework}

We consider livestock the major input in the supply of meat, where livestock has a variety of uses (dairy production, draft animal, cattle raising for export) of which cattle raising for meat is one ${ }^{12}$. Fluctuations in livestock prices cause a shift of the meat supply curve: if demand is held constant, a decrease of the livestock price will shift the meat supply curve to the right and lead to a proportional fall in meat prices. For the meat markets we assume that standard demand and supply analysis applies. Hence, meat prices are adequately described by geographically specified local conditions

\footnotetext{
${ }^{11}$ The coefficient of correlation between poverty rates (IHS2 (2004/2005); IHS3(2010)) and tropical livestock units per head, both by district are positive (not reported, available from the author).

${ }^{12}$ Note that livestock markets are not well developed and tend to be thin leading to extreme and unreliable market prices and missing observations in the data, while meat markets are more regular with sufficient volume on both sides of the market and market price data which are reasonably complete.
} 
and by time related developments that are similar to all markets. The exception that we elaborate on in the current paper is the exogenous shock that arises out of droughts and subsequent crop failures and food shortages.

Droughts, crop failures and food shortages lead to a reduction in livestock value through several mechanisms. The first mechanism is that staple food prices increase tremendously during food shortages, and thereby reduce the real value of livestock. As livestock is used to protect households in case of crop failures and maintain food security, we hypothesize that food shortages lead to increased sales of livestock: as many households will make similar decisions, the additional supply of livestock on the market will reduce livestock prices. Moreover, droughts may also force farmers to sell livestock because access to grazing becomes more limited. On both grounds the supply of livestock on the market increases and livestock prices decrease. With livestock the key input in the production of meat, these development exert a downward pressure on meat prices. Finally, drought and food shortages are likely to impact on the physical condition and body weight of livestock: a drop in the body weight of livestock will also affect the value of livestock negatively ${ }^{13}$, or under extreme conditions cause livestock mortality. We lack detailed data to measure the drop in value due to reduced bodyweight of livestock. However, below we propose a technique to disentangle the reduction in livestock value due to a decrease in meat prices and the reduction in livestock value due to increased staple food prices, and elaborate on the likely additional impact on livestock value of drops in body weight.

\section{Empirical strategy}

In line with the conceptual framework, we postulate that meat prices are empirically determined by local supply and demand conditions, and by food shortages. The key objective of the empirical

\footnotetext{
${ }^{13}$ Barrett et al. 2003 for an elaboration of this mechanism.
} 
estimations is to consider the evidence that that food shortages are negatively correlated with meat prices. We assume that the influence of local supply and demand conditions on spatial meat prices will be fully captured by location and time fixed effects. We start with the following specification: $p_{j t}^{\text {meat }}=\eta_{0}+\eta_{1}$ food shortage $e_{j}+\varphi_{j}+\psi_{t}+\varepsilon_{j t}$

where $p_{j t}^{\text {meat }}$ is the (nominal) price of meat in location $j$ at time $t$, and food shortage $e_{j t}$ is a variable that indicates if location $j$ at time $t$ experiences a food shortage. Parameters $\varphi_{j}$ represent market fixed effects and $\psi_{t}$ time fixed effects, and $\varepsilon_{j t}$ is an error term with zero mean. The equation is a standard Two Way Fixed Effect Difference-in-Difference specification. The important feature of this specification is that it estimates the extent that a food shortage in a specific location raises prices in that location by more than it does in other locations in the same year. Note that the year fixed effects also absorb occasional net imports and ADMARC stock releases at the national level. If households sell livestock during food shortages, we expect that a food shortage has a negative impact of meat prices and hence $\eta_{1}<0$.

Prices of consumer goods and budget compositions of households fluctuate tremendously between years and between locations and, most importantly, within the season. For these reasons using monthly market prices over a long period and for a large number of locations in empirical estimations, makes it necessary to adopt a technique to make meat prices comparable over time and between locations. It is, however, notoriously difficult (and virtually impossible) to find adequate consumer price indices in developing country agricultural settings, for converting local prices into real prices. The available national consumer price index simply fails to take into account differences between prices across locations and is biased towards urban households. We propose the following solution. As subsistence households will normally value their livestock in terms of the quantity of staple food that can be purchased, the natural way to do this is by using staples food 
prices as references prices, in the Malawi case maize prices. Since we have maize prices for a large number of markets (the same number of markets as in case of meat prices), using the terms of trade - the price of meat relative to the price of maize - is an elegant way to avoid the need for consumer prices indices at the district level, that are typically not available. Using the meat-maize terms of trade is also likely to generate a more complete and more accurate picture. The specification changes into:

$p_{j t}^{\text {meat }} / p_{j t}^{\text {maize }}=\eta_{0}+\eta_{1}$ food shortage $e_{j t}+\varphi_{j}+\psi_{t}+\varepsilon_{j t}$

We further propose to approximate food shortages with a physical measure of food shortages: we exploit the dominance of maize in the diet of Malawi population, and construct the requirement of maize by district, as a linear transformation of population and average per capita requirements ${ }^{14}$. We assume that actual previous season maize production relative to current season maize requirements is an adequate approximation of food shortages: values lower than 1 characterize a food shortage. We propose the following adjustment to equation (2): $p_{j t}^{\text {meat }} / p_{j t}^{\text {maize }}=$

$$
\left.\eta_{0}+\eta_{1} \text { [maize production }_{j t-1} / \text { maize requirement }_{j t}\right]+\varphi_{j}+\psi_{t}+\varepsilon_{j t}
$$

Due to its definition, we now expect $\eta_{1}>0$ : a shortage of maize - a deficit of local maize production vis-à-vis local maize requirements - will have a negative impact on the meat-maize terms of trade, and likewise, a relative abundance of maize - a surplus of locally produced maize vis-à-vis local maize requirements - will have a negative impact on the meat-maize terms of trade.

Next, we express our dependent variable - the meat-maize terms of trade - as a betweenyear seasonal change. We replace the terms of trade variable by the seasonal gap, the (log) ratio of

\footnotetext{
${ }^{14}$ See for the construction of the maize requirement variable the section Data, data sources, data availability and variable construction.
} 
the terms of trade in the three pre-harvest months to the same ratio in the three post-harvest months in the previous year ${ }^{15}$. Equation (3) changes into:

$$
\begin{gathered}
\operatorname{gap}\left(p_{j t}^{m} / p_{j t}^{m z}\right)=\left(p_{j}^{\text {meat }} / p_{j}^{\text {maize }}\right)_{\text {preharvest }, t} /\left(p_{j}^{\text {meat }} / p_{j}^{\text {maize }}\right)_{\text {postharvest }, t-1}= \\
\eta_{0}+\eta_{1}\left[\text { maize production }_{j t-1} / \text { maize requirement } \text { prt }_{j t}\right]+\varphi_{j}+\psi_{t}+\varepsilon_{j t}
\end{gathered}
$$

This transformation allows to disentangle effects on meat prices and maize prices: as we can write the $\log$ of a ratio as the difference between the $\operatorname{logs}\left(\ln \left(p^{\text {meat }} / p^{\text {staplefood }}=\ln \left(p^{\text {meat }}\right)-\right.\right.$ $\ln \left(p^{\text {staple food }}\right)$, the decomposition into a 'meat,' and a 'maize' gap equation is straightforward:

$$
\begin{aligned}
& \operatorname{gap}\left(p_{j t}^{\text {meat }}\right)=p_{j \text { preharves }(t)}^{\text {meat }} / p_{j \text { postharvest }(t-1)}^{\text {meat }}= \\
& \quad \zeta_{0}+\zeta_{1}\left[\text { maize production }_{j t-1} / \text { maize requirement }_{j t}\right]+\varphi_{j}+\psi_{t}+\varepsilon_{j t}
\end{aligned}
$$

$$
\begin{aligned}
& \operatorname{gap}\left(p_{j t}^{\text {maize }}\right)=p_{j \text { preharvest }(t)}^{\text {maize }} / p_{j \text { postharvest }(t-1)}^{\text {maize }}= \\
& \vartheta_{0}+\vartheta_{1}\left[\text { maize production }_{j t-1} / \text { maize requirement }_{j t}\right]+\xi_{j}+\omega_{t}+\varepsilon_{j t}
\end{aligned}
$$

Obviously, the coefficients of the food shortage proxy will be different for the meat equation and the maize equation. To illustrate the seasonal gap in meat prices vis-à-vis the seasonal gap in maize prices, Figure $3 \mathrm{a}$ and $3 \mathrm{~b}$ show these gaps for the different identified meats and maize in two specific markets. The figures confirm a consistently opposite movement of meat price gaps and maize price gaps during food shortages. The size of the maize price increases is, however, of a much a larger scale than the meat price decreases.

\footnotetext{
${ }^{15}$ This transformation will relate the analysis more directly to the seasonality literature (Kaminski et al., 2016; Gilbert et al., 2017).
} 
Figure 3a Seasonal gap in meat and maize prices, Mitundu market (Lilongwe district) $200 \%$

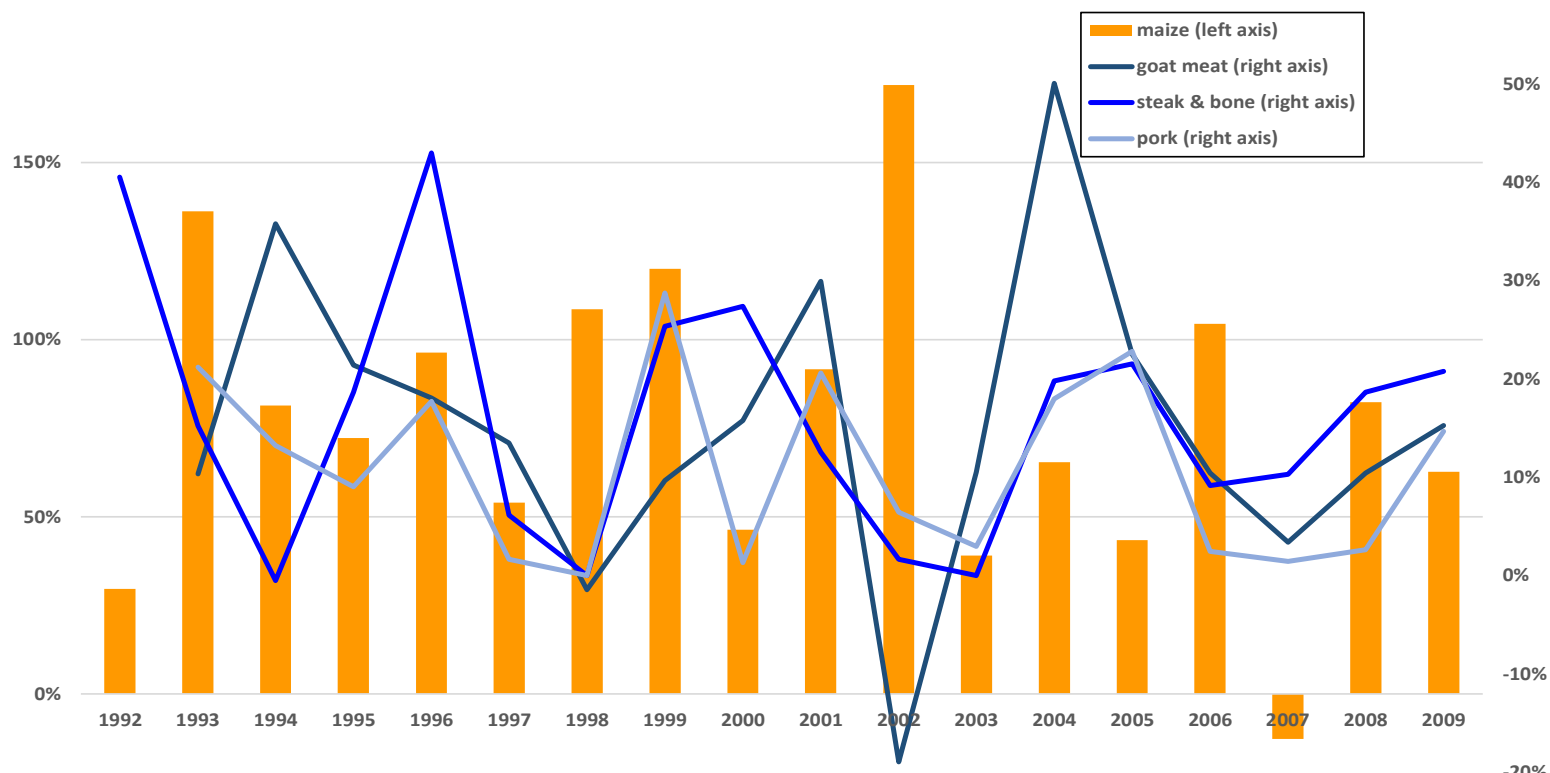

$-50 \%$

Figure 3a Seasonal gap in meat and maize prices, Lizulu market (Ntcheu district)

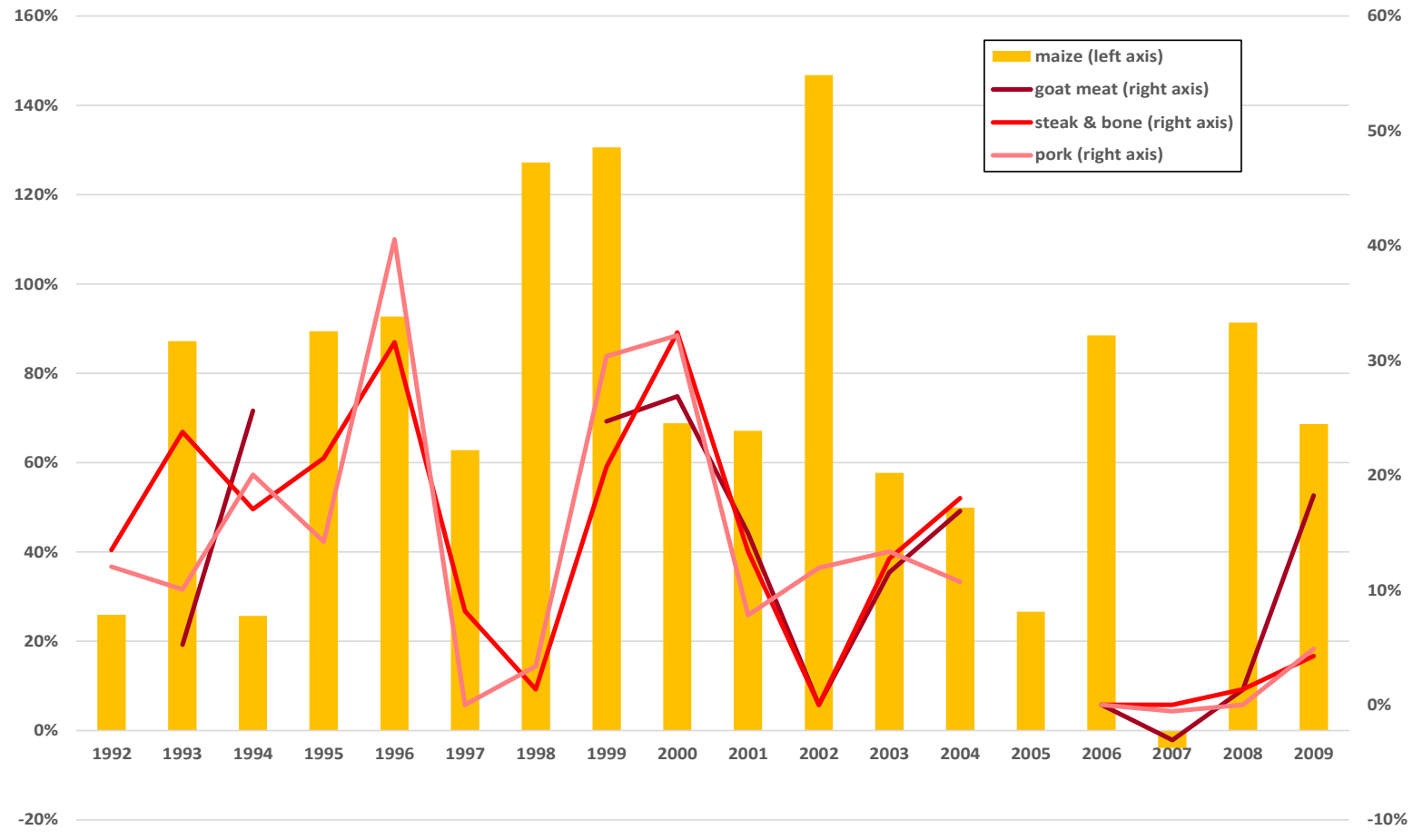

Note: The figure shows the maize and meat price gap for specific markets. Price gaps are calculated as the average price in January, February and March in a specific year (the lean season prices), relative to the average price of the lowest three prices from May to November of the previous year, for a specific market. Source: calculations based on price data from the Agro-Economic Survey, Ministry of Agriculture and Food Security, Government of Malawi. 
The figure also highlights that the meat price gaps move fairly independently from each other outside years of food shortage. In line with this observation, we hypothesize that the abundancescarcity variable is likely to impact meat prices in an asymmetric way: no impact under normal circumstances and a significant impact in case of food shortages. It is straightforward to split the explanatory variable into abundance-scarcity with food shortage, and abundance-scarcity without food shortages $\left(\right.$ maize production $_{j t-1} \leq$ or $>$ maize requirement $_{j t}$ ). These changes are incorporated in equation $5,5 \mathrm{a}$ and $5 \mathrm{~b}$.

$\operatorname{gap}\left(p_{j t}^{m} / p_{j t}^{m z}\right)=\eta_{0}+\eta_{1}\left(a b s c_{j t}\right)_{\mid \text {shortage }}+\eta_{2}\left(\operatorname{absc}_{j t}\right)_{\mid \text {no shortage }}+\varphi_{j}+\psi_{t}+\varepsilon_{j t}$

$\operatorname{gap}\left(p_{j t}^{\text {meat }}\right)=\zeta_{0}+\zeta_{1}\left(a b s c_{j t}\right)_{\mid \text {shortage }}+\zeta_{2}\left(a b s c_{j t}\right)_{\mid \text {no shortage }}+\varphi_{j}+\psi_{t}+\varepsilon_{j t}$

$\operatorname{gap}\left(p_{j t}^{\text {maize }}\right)=\vartheta_{0}+\vartheta_{1}\left(a b s c_{j t}\right)_{\mid \text {shortage }}+\vartheta_{2}\left(a b s c_{j t}\right)_{\mid \text {no shortage }}+\xi_{j}+\omega_{t}+\varepsilon_{j t}$

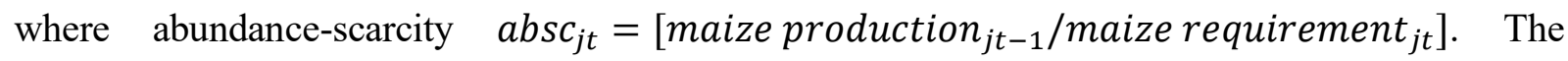
indicator shortage conditions the abundance-scarcity variable to be equal to measured abundance-scarcity if maize production $_{j t-1} \leq$ maize requirement $_{j t}$, and zero elsewhere, while the indicator no shortage does the reverse. We expect $\eta_{1}, \zeta_{1}$ and $\vartheta_{1}$ to be significant and $\eta_{2}, \zeta_{2}$ and $\vartheta_{2}$ to be insignificant. Equations 5, 5a and 5b are the basic specifications for the empirical estimations.

With price data for many markets in a geographically limited space, spatial spillovers are very likely. Spatial spillovers potentially affect the estimated relationship and therefore need to be controlled for. We therefore employ fixed effects spatial regression. Estimations allow for spillovers from other markets, through the dependent variable, through the explanatory variable and in the residual. To specify the influence of spatial spillovers we make use of an inverse distance matrix. The inverse distance matrix has zeros on the diagonal, and, by construction, attributes large 
weights to nearby markets and small weights to far-away markets. Spatial spillovers are incorporated in the estimation by including as regressors the product of the inverse distance matrix and the dependent variable, the independent variable and the residual. We estimate this adjusted equation with fixed-effects spatial regression for panel data, available in STATA. Because of high transaction costs and the characteristics of domestic trade (Fafchamps et al., 2005) we have truncated the spatial effects to around $50 \mathrm{~km}$ distance between markets ${ }^{16}$.

Several other concerns are addressed in additional estimations (regional variation, serial and spatial correlation in standard errors, potential endogeneity). We consider regional variation by reestimating the equations separately for the northern, central and southern region. We expect our data to be serially and spatially correlated and consequently estimated standard errors will be inconsistent. Clustering standard errors with the panel identifier, in our case market, results in standard errors that are robust to serial and spatial correlation (Driscoll and Kraay, 1998). Finally, there are potential concerns about endogeneity of the abundance-scarcity variable: we have addressed this by estimating with IV-2SLS and instrumenting the abundance-scarcity variable with rainfall by district.

Data, data sources, data availability and variable construction

The core data for the empirical estimations are monthly market prices for goat meat, steak \& bone, pork and maize, for a total of 72 markets, all sourced from the Agro-Economic Survey, Ministry of Agriculture and Food Security, Government of Malawi ${ }^{17}$. We have chosen the price of goat meat, steak \& bone and pork since these prices correspond with the major livestock categories reared by Malawi households (Appendix, Figure 1$)^{18}$. For some predominantly Islamic districts (Machinga) there is no (or only a limited) market for pork. We have chosen the price of maize as

\footnotetext{
${ }^{16}$ Euclidian distance used in calculating the inverse distance matrix is around $20 \%$ shorter than road distance.

${ }^{17}$ Appendix, Figure A3 shows a map with the geographical location of markets.

${ }^{18}$ The exception is chicken for which Malawi price data are not available.
} 
staple food price, as maize is the major staple food grown and consumed by most Malawi households. From the background section on of Malawi agriculture it is clear that maize dominates both in production and consumption, in all districts of Malawi (and more so relative to many other countries). Cassava is a popular crop in the northern districts that border lake Malawi (Nkhatabay, Nkhotakota, and Karonga), but becoming increasingly popular throughout Malawi. Rice is especially grown in Karonga in the north, and Machinga and Zomba in the south, and primarily consumed in the cities.

The availability of price data increases drastically after January 2004: from this date onwards observations increase, for all series, from less than $30 \%$ to nearly $80 \%$ of all locations (Appendix, Figure A2). The background of this increase is purely a change in the coverage of markets by the administrative organisation that collects the market price data (Agro-Economic Survey, Ministry of Agriculture and Food Security, Government of Malawi). Additionally, the data suffer from missing observations reflecting lack of supply in the market and associated with seasonality. This is common to agricultural price series. Since we are particularly interested in prices during lean season, it may possibly affect the estimations. However, missing lean season observations fortunately do not jeopardise are empirical estimations, partly due to the aggregation of monthly data into annual observations.

For the construction of a variable reflecting maize abundance-scarcity by district we have used census based population data by district (Rural Development Project) from the National Statistical Office - dated 1987, 1998 and 2008 - that are interpolated for intermediate months, and annual maize production data, also sourced from Agro-Economic Survey, Ministry of Agriculture and Food Security, Government of Malawi. Rainfall data, used to instrument maize production, are from the Department of Climate Change and Meteorological Service in Zomba, 
and are available for 31 locations. Monthly rainfall observations, aggregated by season - where the season runs from April to March - are first attributed to Extension Planning Areas (EPAs, 102 in total) and subsequently averaged by district (Rural Development Project). For descriptive purposes we have shown real prices of meat and staple foods, calculated by using the Malawi consumer price index for deflation, which is sourced from the IMF International Financial Statistics database. Malawi has a total of 26 districts (Rural Development Project (RDPs)), eight Agricultural Development Divisions (ADDs) and three regions (north, central and south): Appendix, Table A2 shows how the 72 markets for which we have price data, RDPs, ADDs and regions are related. The latitude-longitude coordinates of markets needed for the spatial estimations are taken from Google maps.

The abundance-scarcity variable is constructed by exploiting the dominance of maize in the diet of Malawi population: it is defined as actual previous year maize production versus the households requirements of maize for consumption, both by district. Values lower than 1 of the abundance-scarcity variable characterize a food shortage. Households requirements of maize for consumption are a simple transformation of district population. Maize required for basic nutrition per person is equal to maize kcal share in the diet times the total kcal needs per person, divided by $\mathrm{kcal}$ content per $\mathrm{kg}$ of maize. Unfortunately we only have country averages for diet shares and kcal needs based on case studies. Hence, we calculate maize required for basic nutrition, in district $j$ and date $t$ as follows:

$r e q_{j t}=\left(\right.$ pop $_{j t} *$ share in diet $*$ needs per person $) /$ maize kcal content per $\mathrm{kg}$ For the average maize kcal share we use 0.5 and 0.65 and for average kcal needs per person (per day) we use $2100 \mathrm{kcal}$ and $2300 \mathrm{kcal}$. The per $\mathrm{kg} \mathrm{kcal}$ content of maize is 3570 , which completes the construction of maize requirements (Zant, 2012). Applied to the data the abundance-scarcity 
variable confirms documented food shortages and also shows substantial geographical variation (Appendix, Figure A4). Documented food shortages are confirmed by the development of the abundance-scarcity variable over the years. The maize abundance-scarcity variable also supports pronounced variation between districts. The plots of the maize abundance-scarcity variable further indicate a larger intensity of food shortages during 1992-93 and 1994-95, relative to 2005-06. This contrasts with observed food price increases which are larger during the 2005-2006 food shortage. The use of the abundance-scarcity variable implicitly assumes that the geographical variation in crop outcomes and population density, jointly with high transaction $\cos { }^{19}{ }^{19}$ create sufficient differences across locations ${ }^{20}$.

\section{Estimations and robustness checks}

We start with estimating the basic specification, equation (5, 5a and 5b). Apart from indicator variables, both the dependent variable - the meat-maize terms of trade gap, the meat gap and the maize gap - and the abundance-scarcity variable are transformed into natural logarithms. This transformation allows the interpretation of coefficients in terms of elasticities. Estimation results, reported in Table 1, confirm that the impact of food shortages on meat-maize terms of trade is statistically significant - nearly all at the $1 \%$ level - with the expected sign for all meat prices. More importantly: food shortages widen the maize price gap, as expected, but lead to an opposite movement in the meat price gap. The estimations further support the asymmetric impact of the abundance-scarcity variable: coefficients during no shortage periods are without exception insignificant. The positive and significant coefficients in the meat price gap estimations (column 2) is clear support for increased livestock sales during food shortages.

\footnotetext{
${ }^{19}$ See Zant, 2013.

${ }^{20} \mathrm{We}$ also formally investigate if this assumption is supported by the data (Estimations and robustness checks).
} 


\begin{tabular}{|c|c|c|c|}
\hline dependent variable: & $\begin{array}{c}(1) \\
\ln \left(\text { gap }^{\text {goat/ }} \text { gap }^{\text {maize }}\right)\end{array}$ & $\begin{array}{c}(2) \\
\ln \left(\text { gap }^{\text {goat }}\right)\end{array}$ & $\begin{array}{c}(3) \\
\ln \left(\text { gap }^{\text {maize }}\right)\end{array}$ \\
\hline $\ln \left(q^{\text {maize }}{ }_{t-1} / \text { req }^{\text {maize }} t\right)_{\text {|shortage }}$ & $0.263^{* * *}(0.082)$ & $0.034^{* * *}(0.012)$ & $-0.170^{* * *}(0.049)$ \\
\hline $\ln \left(\mathrm{q}^{\text {maize }}{ }_{\mathrm{t}-1} / \mathrm{req}^{\text {maize }} \mathrm{t}\right) \mid$ no shortage & $0.086 \quad(0.088)$ & $0.034 \quad(0.024)$ & $-0.053 \quad(0.058)$ \\
\hline $\mathrm{R}^{2}$ & 0.797 & 0.461 & 0.781 \\
\hline no. of observations & 376 & 415 & 478 \\
\hline dependent variable: & $\ln \left(\right.$ gap $^{\text {steak\&bone }} /$ gap $\left.^{\text {maize }}\right)$ & $\ln \left(\right.$ gap $\left.^{\text {steak\&bone }}\right)$ & $\ln \left(\right.$ gap $\left.^{\text {maize }}\right)$ \\
\hline $\ln \left(q^{\text {maize }}{ }_{t-1} / \text { req }^{\text {maize }} t\right)_{\text {shortage }}$ & $0.195^{* * *}(0.060)$ & $0.032^{* * *}(0.008)$ & $-0.170^{* * *}(0.049)$ \\
\hline $\ln \left(\mathrm{q}^{\text {maize }}{ }_{\mathrm{t}-1} / \mathrm{req}^{\text {maize }} \mathrm{t}\right)$ |no shortage & $0.047 \quad(0.056)$ & $-0.012 \quad(0.018)$ & $-0.053 \quad(0.058)$ \\
\hline $\mathrm{R}^{2}$ & 0.788 & 0.558 & 0.781 \\
\hline no. of observations & 415 & 463 & 478 \\
\hline dependent variable: & $\ln \left(\right.$ gap $^{\text {pork}} /$ gap $\left.^{\text {maize }}\right)$ & $\ln \left(\right.$ gap $\left.^{\text {pork }}\right)$ & $\ln \left(\right.$ gap $\left.^{\text {maize }}\right)$ \\
\hline $\ln \left(\mathrm{q}^{\text {maize }}{ }_{\mathrm{t}-1} / \mathrm{req}^{\text {maize }}\right)_{\text {|shortage }}$ & $0.181^{* *}(0.073)$ & $0.059^{* * *}(0.022)$ & $-0.170^{* * *}(0.049)$ \\
\hline $\ln \left(q^{\text {maize }}\right.$ t-1/req $\left.{ }^{\text {maize }} t\right)$ |no shortage & $0.051 \quad(0.080)$ & $0.000 \quad(0.020)$ & $(0.058)$ \\
\hline $\mathrm{R}^{2}$ & 0.829 & 0.473 & 0.781 \\
\hline no. of observations & 354 & 379 & 478 \\
\hline
\end{tabular}

Note: Price gaps are calculated as the average price in January, February and March in a specific year (the lean season prices), relative to the average price of the lowest three prices from May to November of the previous year, for a specific market. The source data are monthly market price observations for 72 locations (markets, villages and towns), from January 1991 to October 2009, taken from Agro-Economic Survey, Ministry of Agriculture and Food Security, Government of Malawi (see data section for further details). Equations are estimated with OLS. All estimations include location (market) and time (year) fixed effects. Standard errors clustered by market are reported in brackets below the coefficient. ${ }^{*} p<0.10,{ }^{* *} p<0.05,{ }^{* * *} p<0.01$.

Robustness checks, documented in the Appendix (Table A3 to A8), by and large support the results reported in Table 1. Estimation by region point to regional heterogeneity: the relationship is supported in estimations for the south and the north, but much less (not) in estimations for the central region. We also find stronger support (higher and more significant coefficients) for rural areas vis-à-vis urban areas. Controls (serial correlation in errors) and alternative estimation techniques (Fixed Effects (FE), Instrumental Variables - Two Stage Least Squares) generate similar coefficients.

Prior to considering the size of impacts and the economic implications of the estimations of the meat-maize terms of trade, we report estimations of another robustness check, one that controls for spatial correlation. Direct and total impacts are reported in Table 2 and the underlying estimations are reported in the appendix. In terms of the sign and significance of the coefficients, Table 2 and Table 1 estimations are similar. All direct and total impacts on either the meat price 
gap, the maize price gap of the meat-maize term of trade gap are statistically significant, mostly at the $1 \%$ level and have the expected sign. However, spatial spillovers are statistically well supported, most convincingly in the maize price gap estimations. The difference between direct and total impact is large in the maize price gap (with indirect impact $69 \%$ of total), negligible in the meat price gap and in between in the meat-maize term of trade gap (indirect impact $11 \%-57 \%$ of total). Overall, Table 2 coefficients with spatial spillovers, both direct and total, are much higher than Table 1 OLS coefficients, except for the coefficients in meat price gap estimation (direct impact in case of the meat-maize terms of trade gap, ranging from 0.041 to 0.47 (T2), compared to 0.032 to 0.059 (T1)). In summary, controlling for spatial spillovers reveals a substantial contribution of surrounding markets and has a major impact on the size of the estimated coefficients, particularly the coefficients in maize price gap and meat-maize term of trade gap estimation.

The evidence, reported in Table 1 and 2, indicates that the meat-maize terms of trade has decreased during food shortages. The decomposition into meat and maize price gaps shows that the bulk of the decrease originates from the increase in the maize price gap (T1: 77\%-86\%; T2: 79\%-91\%), and a modest part (T1: 14\%-23\%; T2: 9\%-21\%) from the decrease of the meat price gap. The estimates are consistent with increased livestock sales and support the hypotheses that the value of livestock have decreased during food shortages. With the double logarithmic specification coefficient can be interpreted as elasticities: considering the total impact with spatial spillovers, a $100 \%$ decrease of the abundance-scarcity variable leads to a decrease in meat-maize terms of trade varying from $54 \%$ to $65 \%$. During food shortages observed decreases of the district abundance-scarcity variable ranged from $50 \%$ to $100 \%$. 
Table 2 Meat-Maize Gaps versus Maize Abundance-Scarcity, fixed effect spatial regression, 1992-2009

\begin{tabular}{|c|c|c|c|}
\hline \multirow{5}{*}{ 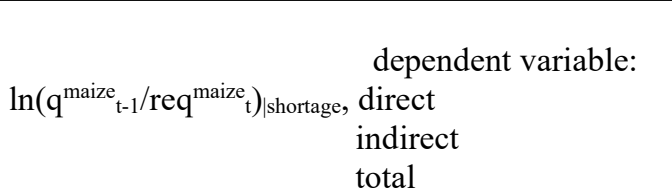 } & (1) & (2) & (3) \\
\hline & $\ln \left(\right.$ gap $^{\text {goat }} /$ gap $\left.^{\text {maize }}\right)$ & $\ln \left(\right.$ gap $\left.^{\text {goat }}\right)$ & $\ln \left(\right.$ gap $\left.^{\text {maize }}\right)$ \\
\hline & $0.421^{* * *}(0.093)$ & $0.041^{* *}(0.018)$ & $-0.135^{* *}(0.054)$ \\
\hline & $(0.164)$ & $(0.012)$ & $-0.296^{* * *}(0.063)$ \\
\hline & $0.649^{* * *}(0.199)$ & $0.043^{* * *}(0.015)$ & $-0.431^{* * *}(0.100)$ \\
\hline \multirow{4}{*}{$\begin{array}{l}\text { Wald chi2 }(5) ;(\text { Prob }>\text { chi2) } \\
\text { pseudo } \mathrm{R}^{2} \\
\text { Wald test of spatial terms: chi2 }(4) ;(\text { Prob }>\text { chi2 }) \\
\text { no. of observations / no of groups }\end{array}$} & $37.92(0.0000)$ & $15.35(0.0090)$ & $43.79(0.0000)$ \\
\hline & 0.0248 & 0.0084 & 0.0297 \\
\hline & $37.27(0.0000)$ & $11.87(0.0183)$ & $106.2(0.0000)$ \\
\hline & $170 / 17$ & $170 / 17$ & $196 / 14$ \\
\hline \multirow{8}{*}{ 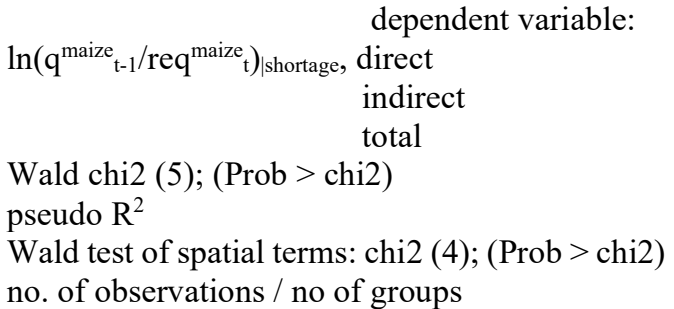 } & $\ln \left(\right.$ gap $^{\text {s\&b }} /$ gap $\left.^{\text {maize }}\right)$ & $\ln \left(\right.$ gap $\left.^{\text {steak\&bone }}\right)$ & $\ln \left(\right.$ gap $\left.^{\text {maize }}\right)$ \\
\hline & $0.306^{* * *}(0.064)$ & $0.045^{* * *}(0.045)$ & $-0.135^{* *}(0.054)$ \\
\hline & $0.235^{* * *}(0.065)$ & $-0.005 \quad(0.004)$ & $-0.296^{* * *}(0.063)$ \\
\hline & $0.541^{* * *}(0.541)$ & $0.040^{* * *}(0.013)$ & $-0.431^{* * *}(0.100)$ \\
\hline & $49.99(0.0000)$ & $15.56(0.0082)$ & $43.79(0.0000)$ \\
\hline & 0.0236 & 0.0188 & 0.0297 \\
\hline & $81.43(0.0000)$ & $8.32(0.0805)$ & $106.2(0.0000)$ \\
\hline & $240 / 15$ & $198 / 18$ & $196 / 14$ \\
\hline \multirow{8}{*}{$\begin{array}{l}\ln \left(\mathrm{q}_{\mathrm{t}-1}^{\text {maize }} / \mathrm{req}_{\mathrm{t}}^{\text {maize }}\right)_{\mid \text {shortage, }} \begin{array}{l}\text { direct } \\
\text { indirect } \\
\text { Total }\end{array} \\
\text { Wald chi2 }(5) ;(\text { Prob }>\text { chi2 }) \\
\text { pseudo } \mathrm{R}^{2} \\
\text { Wald test of spatial terms: chi2 }(4) ;(\text { Prob }>\text { chi2 }) \\
\text { no. of observations / no. of groups }\end{array}$} & $\ln \left(\right.$ gap $^{\text {pork }} /$ gap $\left.^{\text {maize }}\right)$ & $\ln \left(\right.$ gap $\left.^{\text {pork }}\right)$ & $\ln \left(\right.$ gap $\left.^{\text {maize }}\right)$ \\
\hline & $0.485^{* * *}(0.111)$ & $0.047^{* *}(0.019)$ & $-0.135^{* *}(0.054)$ \\
\hline & $0.060 \quad(0.097)$ & $0.071^{* * *}(0.021)$ & $-0.296^{* * *}(0.063)$ \\
\hline & $0.545^{* * *}(0.181)$ & $0.118^{* * *}(0.023)$ & $-0.431^{* * *}(0.100)$ \\
\hline & $26.22(0.0001)$ & $29.49(0.0000)$ & $43.79(0.0000)$ \\
\hline & 0.0241 & 0.0289 & 0.0297 \\
\hline & $13.95(0.0074)$ & $11.77(0.0192)$ & $106.2(0.0000)$ \\
\hline & $143 / 13$ & $168 / 14$ & $196 / 14$ \\
\hline
\end{tabular}

Note: Price gaps are calculated as the average price in January, February and March in a specific year (the lean season prices), relative to the average price of the lowest three prices from May to November of the previous year, for a specific market. The source data are monthly market price observations for 72 locations (markets, villages and towns), from January 1991 to October 2009, taken from Agro-Economic Survey, Ministry of Agriculture and Food Security, Government of Malawi (see data section for further details). The fixed effect spatial regression (spxtreress) specifies spatial correlation of the dependent variable, the explanatory variable and the error term. The inverse-distance matrix has zero weights for locations more than $50 \mathrm{~km}$ apart. Estimations include both abundance-scarcity variables but only report this variables under shortage. The table reports the average impacts (estat impact). Standard errors are reported in brackets next to the coefficient. ${ }^{*} p<0.10,{ }^{* *} p<0.05,{ }^{* * *} p<0.01$.

For several reasons, however, even this large drop in livestock value severely underestimates the actual drop. The time fixed effects absorb the country-wide covariant part of impact: coefficients further increase without time fixed effects. Next, the estimations report averages and employ district aggregates in the key explanatory variable, which both conceal distributions while food shortages occur in the tail of distributions. For these reasons, it is more informative to take a closer look at the change in meat-maize terms of trade during food shortages per se and consider the estimation results useful to provide sound support for the negative correlation between meat-maize 
terms of trade and food shortages. From a food-security perspective a typical household is, in the end, indifferent where the drop in livestock value comes from. What matters for households is to have sufficient food to survive a food shortage.

\section{Alternative explanations}

We discuss two alternative explanations of a drop in the value of livestock. First, the same weather conditions that lead to a crop failure may result in underfed cattle which than command lower prices in the market. A drop in body weight and health of livestock during a food shortage due to underfeeding is clearly a channel that directly affects the value of livestock to the household (Barrett et al, 2003). However, such a drop in value is likely to be concentrated in the volume or quantity rather than the price of meat: $1 \mathrm{~kg}$ of meat from well-fed or underfed cattle will fetch more or less similar prices. It is especially a drop in the quantity, the volume of meat, that arises due to underfeeding. Consequently, the potential additional reduction in livestock value arising out of underfeeding, makes the measured drop in value a lower bound of the actual loss in value.

Secondly, the price inelasticity in maize demand may result in a strong negative income effect on the demand for food, which also reduces meat prices. If the price inelasticity in maize demand results in a strong negative income effect on the demand for food, such an effect would decrease maize prices. The evidence tells a different story: the extreme increase in prices of staples foods suggest that the drop in supply dominates the possible negative income effect. It is even consistent with increases in demand. A drop in the demand for meat due to a negative income effect is also an unconvincing explanation of the observed drop in meat prices. Many households are subsistence farmers and do not purchase or sell on the market. However, with a crop failure households are forced to purchase food on the market with their available savings, mainly livestock. Also, households that normally would sell maize on the market, have to purchase maize 
on the market in case of a crop failure. Hence, a food shortage triggers increased staple food demand on the market complemented with increased livestock supply on the market from most households.

\section{Taking a closer look at the meat-maize terms of trade}

With the size of the key coefficient varying by type of livestock and staple food, by sample period and by region, focusing on specific periods may yield different outcomes. We therefore investigate the period of the 2005-2006 food shortage, from February-March 2005 to February-March 2006. Figure 4 illustrates graphically the development of the goat meat-maize terms-of-trade, supporting an extreme drop of the relative value of goat meat during the climax of this food shortage.

\section{Figure 4 Goat meat - maize terms of trade, 2005-2006 food shortage, Malawi}

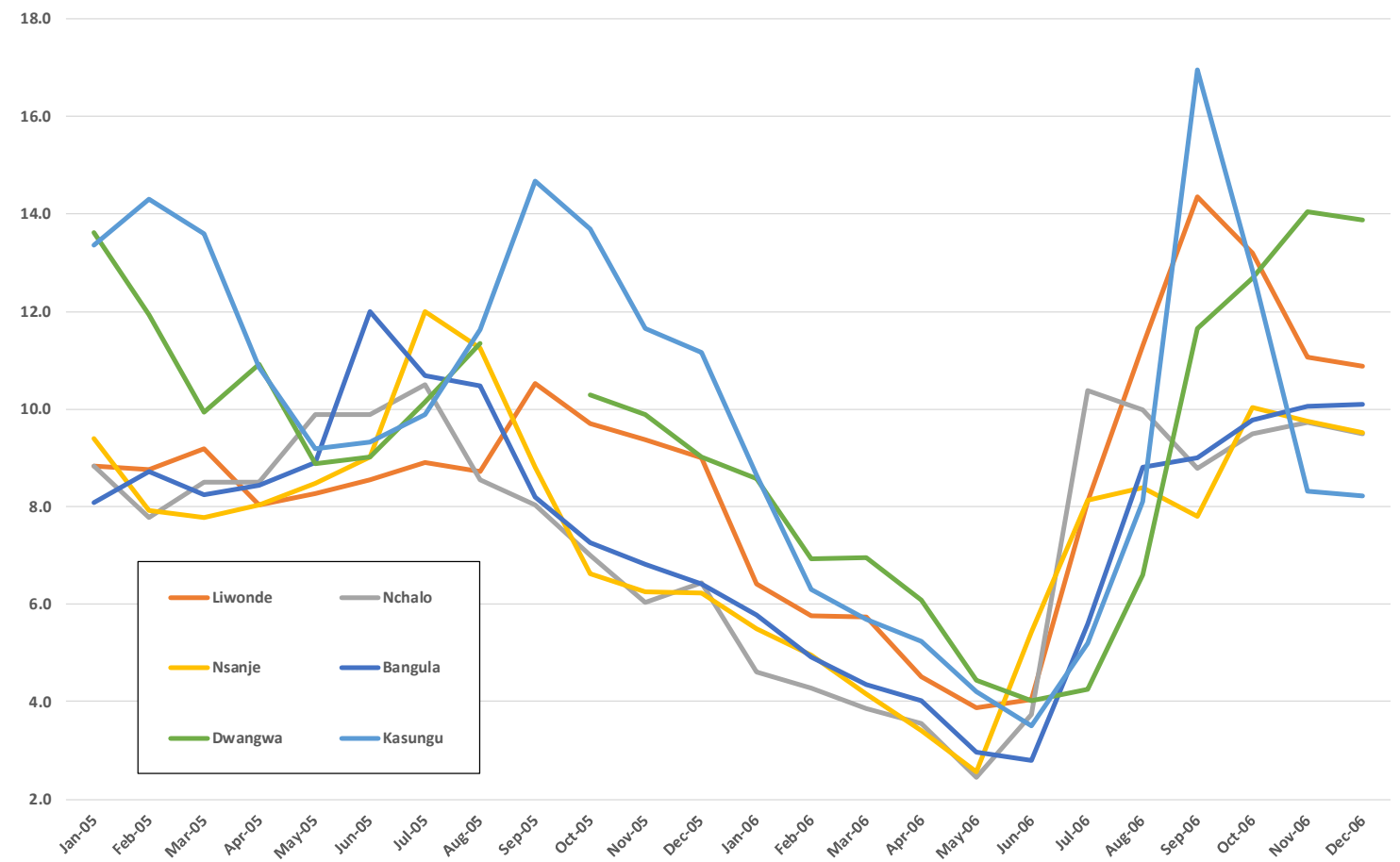

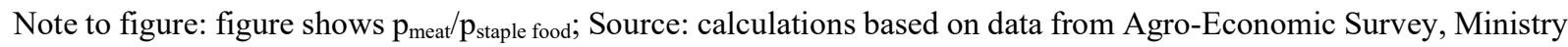
of Agriculture and Food Security. 
As already hinted at in the previous section, a more direct measurement of the size of the reduction of the wealth value of livestock will be more informative and can be obtained by simply summarizing the change in meat-maize terms of trade during specific periods of food shortage. The major food shortage episodes in Malawi in our sample occur in 1997-1998, 2001-2002 and 2005-2006. Table 3 reports the relative change in meat-maize terms of trade during food shortages, calculated as the average terms of trade from January to March - the lean season months in Malawi - relative to these terms of trade in the post-harvest months during the previous year. The relative change is calculated for all villages, towns and cities recorded in the data, and subsequently averaged over all these locations. The table indicates that the average meat-maize terms of trade decreased during these episodes from $56 \%$ to $73 \%$. The estimated decrease in livestock value is likely to be an underestimate since our data do not allow to measure the reduction in value due to a lower body weight of livestock during food shortages (see also Alternative explanations).

Table 3 Meat-maize price gaps ( $\%$ change in meat-maize terms of trade)

\begin{tabular}{l|ccc|ccc|ccc}
\hline \hline & \multicolumn{3}{|c|}{$1997-1998$} & \multicolumn{3}{c|}{$2001-2002$} & \multicolumn{3}{c}{$2005-2006$} \\
& avg. & min. & max. & avg. & min. & max. & avg. & min. & max. \\
\hline goat meat - maize & -55.7 & -66.7 & -44.3 & -70.9 & -85.4 & -44.8 & -56.2 & -74.4 & -27.2 \\
steak \& bone -maize & -60.7 & -73.6 & -44.3 & -71.3 & -85.4 & -44.8 & -55.8 & -73.3 & -23.9 \\
pork - maize & -58.7 & -71.0 & -44.3 & -72.8 & -85.4 & -46.7 & -55.7 & -75.4 & -27.2 \\
\hline \hline
\end{tabular}

Note: The table reports the average price in January, February and March in a specific year (the lean season prices), relative to the average price of the lowest three prices from May to November of the previous year, by market, and averaged over markets. Source: calculations based on Agro-Economic Survey, Ministry of Agriculture and Food Security, Government of Malawi.

Another interesting period is the period from early 2008 to late 2009. During this period staple food prices in Malawi increased substantially (Appendix, Figure A2). However, this price increase originated from the world market and had no relation with the domestic agricultural outcome in Malawi. During this period staple foods were available in reasonable quantities in the domestic 
market $^{21}$. We can verify our results by exploring the 2008-2009 development of the meat price gaps. If the hypothesis holds that accumulated savings in the form of livestock are especially liquidated (sold on the market) during food shortages, we should observe that during this period meat prices respond much less to the relative abundance-scarcity of maize (what is produced visa-vis what is needed domestically). And, indeed, unlike other high price food shortage periods, the large maize price increases in 2008 and 2009 are combined with substantial increases in meat prices (Figure 1), indicating normal and not excess supply of livestock.

\section{Figure 5 Meat - maize terms of trade, 2011 food shortage, Uganda}

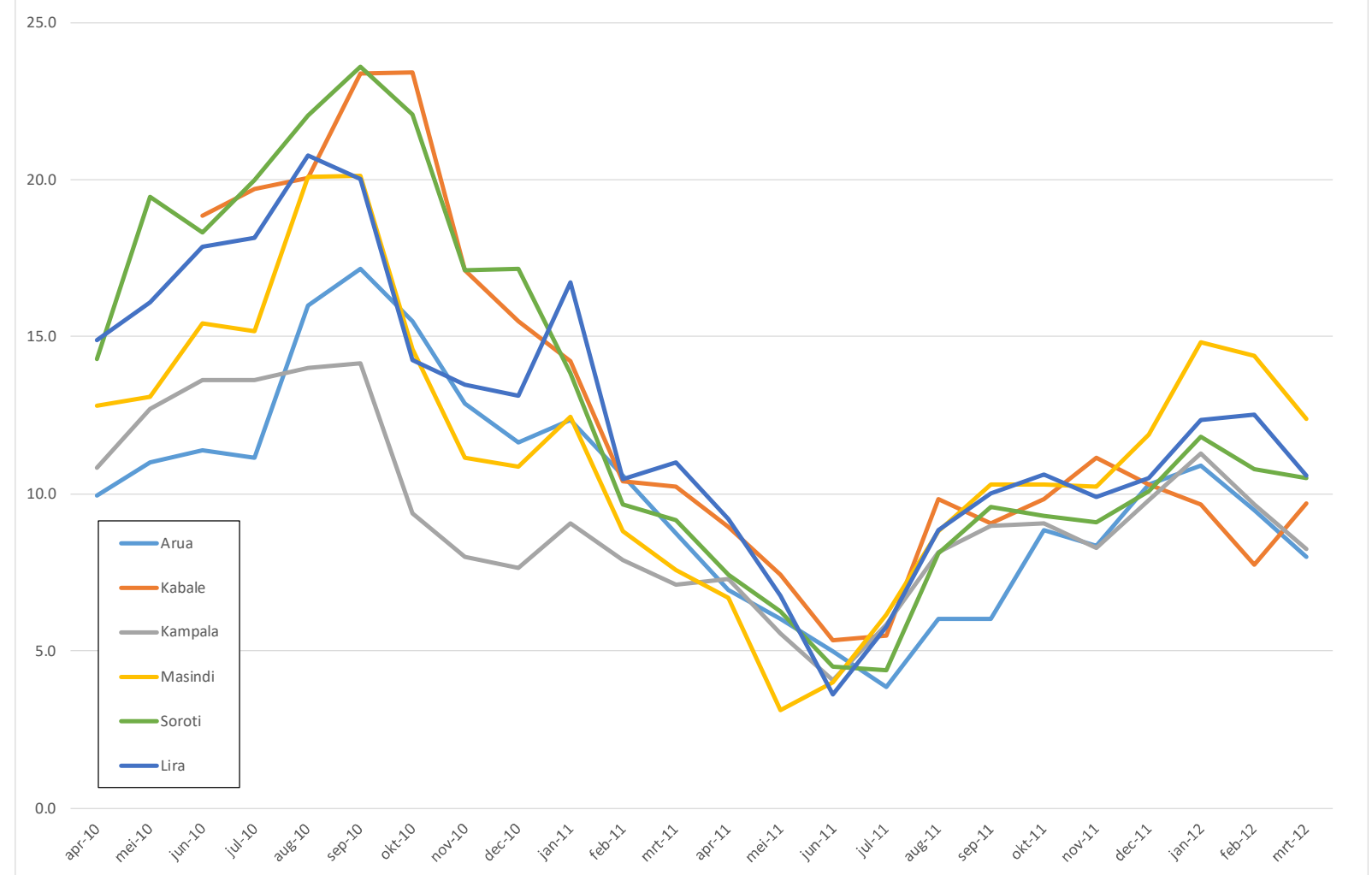

Source: figure shows $\mathrm{p}_{\text {meat }} / \mathrm{p}_{\text {staple food }}$; calculations based on data from ASARECA-ReSAKKS

\footnotetext{
${ }^{21}$ For 2008 and 2009 the abundance-scarcity variable is above 1 for most markets.
} 
Meat-staple food terms of trade during food shortages in other SSA countries

Similar developments in meat-staple food terms of trade are observed in many sub-Sahara African countries. Figure 3 shows the meat-maize terms of trade in Uganda during the 2011 food shortage. Figures A5a-g in the Appendix show additional and similar evidence for several countries (Uganda, Kenya and Somalia), for several meats, for several staple foods and during several periods of food shortage ${ }^{22}$. In short, the experience in many sub-Sahara African countries indicate a systematic pattern of large drops in meat-staple food terms of trade during food shortages and associated with drops in the value of livestock.

\section{Implications of outcomes and policy alternatives}

\section{Implications for households}

How does the drop in livestock value affect the average household? With a simple back-of-theenvelope calculation one can highlight to what extent a typical household can cover staple food expenditure during a food shortage. Using price data for the 2005-2006 season we observe that the terms of trade for goat meat versus maize from February 2005 to February 2006 deteriorated by a factor of four. Making a number of assumptions ${ }^{23}$, we calculate that, with a crop failure, households

\footnotetext{
${ }^{22}$ The selection of countries is conditioned by the availability of complete monthly price series of meats (or livestock) and staple foods, at the level of cities and towns, in SSA countries, that cover a food shortage period, and can be accessed in the public domain.

${ }^{23}$ A typical household - 6 persons: 2 adults, 2 teen-agers, and 2 children below 10 years of age - that grows maize for home consumption requires around $700 \mathrm{~kg}$ of maize for a whole year, equivalent to around $54 \mathrm{~kg}$ per month, to adequately feed all household members. The quantity of maize required to feed a household is calculated as follows: [2 (adults) $\mathrm{x}$ 2300 (daily kcal requirement of adults) + 2 (teenagers) x $1800+2$ (children) x 1200)] x 60\% (maize calorie share in household diet) x 365 (number of days per year) / 3570 (per kg kcal content of maize). We calculate the market value of selling goats by this household in terms of maize. We propose that the household can sell two goats. Goats have a weight of $30 \mathrm{~kg}$ and the meat content of a goat is $25 \mathrm{~kg}$. With a complete crop failure and assuming that households fully and perfectly anticipate maize prices and household maize needs in the remaining marketing season, the household sells its two goats directly after harvesting time and - also directly after harvesting time - purchases maize. With these assumptions households can cover approximately $33 \%$ of maize needed till the next harvest with livestock sales. With an average reproduction rate of around $60 \%$ per year and depending on the size of the household herd before the foodshortage, it might take a few years to recover the previous household herd of livestock, and to re-establish pre-foodshortage levels of food security.
} 
can cover approximately $33 \%$ of expenditure on maize needed till the next harvest with livestock sales. Larger livestock herds per household obviously allow larger contributions, but given the average numbers this cannot be expected. On the contrary, it is not difficult to envisage circumstances that are less favorable. For example, a smaller livestock herd, delayed or sequential sale of goats, unfavorable farm gate versus market prices (both for sales of livestock and for purchases of maize) or limited maize storage capacity all further decrease this contribution. The options for households drastically deteriorate if the value of livestock depreciates in the course of the food shortage. These numbers - the share of household consumption that can be covered with livestock sales in case of crop failure - come close to what is found elsewhere in the literature (Fafchamps et al., 1998; Kazianga and Udry, 2006). The observed preference for using grain stocks to bridge periods of lack staple food is clearly not an issue of liquidity (Kazianga and Udry, 2006; Mogues, 2011): in contrast with livestock, grain stocks do not lose value during a food shortage.

The extreme drop in livestock value during food shortages highlights a major drawback of using livestock sales to overcome adverse impacts of crop failures. A savings device that drastically decreases in value when needed is a poor savings device ${ }^{24}$. An adequate savings device should not lose value at the very moment when it is liquidated. The lack of adequate savings devices creates obvious risks: it makes it more difficult to protect and maintain food security, and it aggravates the risk of agricultural production. In case of credit constraints and risky agriculture, Dercon $(1998,2002)$ shows that low income households tend to choose low return-low risk activities. With savings instruments that adequately protect against food shortages, households have better opportunities to take up high return-high risk activities (like cash crops or cattle

\footnotetext{
${ }^{24}$ The more general message is that agricultural households in developing countries suffer rather than benefit from seasonality: households sell agricultural output when prices are low: livestock during food shortage, but also, staple food crops directly after harvest. Most households also purchase staple food when prices are high, in the lean season or during food shortages. There are substantial and largely unexploited arbitrage opportunities (Burke at al., 2019).
} 
rearing). The long run effects of eliminating ex-ante risk on welfare and growth are shown to be large (Elbers et al 2007).

Dampening supply shocks and tilting the demand curve

What possibilities are there to improve the quality of livestock savings? And what alternative savings devices are available? The trivial but unsatisfactory answer is to avoid crop failures in agriculture. Nevertheless, making agriculture less sensitive to the vagaries of the weather through wider application of irrigation, water harvesting and conservational cultivation techniques will dampen peaks in staple food prices and thereby also strengthen the adequacy of using livestock as a savings device. An alternative way to dampen supply shocks is to make staple food imports less costly. Improved transport links, in the first place to South Africa, Mozambique (Nacala) and Tanzania (Dar es Salaam), but also domestically, have the potential to make Malawi less selfreliant with the result that staple food prices would be less sensitive to domestic production. A more modest increase in staple food prices will automatically also improve the usefulness of livestock savings.

Another way to improve the adequacy of livestock as a savings device is to diversify staple food demand. The highly inelastic maize demand in Malawi is driven by traditionally strong consumer preferences (Smale, 1995). A larger response to prices or a flatter maize demand curve would significantly reduce extreme maize price increases during food shortages. Substitution into other staple foods will increase responses to maize price increases. Rice and cassava are obvious candidates, sorghum also works well: diversification of the consumption diet into these staples will contribute to make the demand curve flatter, mitigate price staple food price increases during food shortages and, jointly with this, reduce the drop in livestock value. 


\section{Formal savings and insurance instruments}

Putting an alternative savings device in place, like a formal bank or savings account, or a formal insurance, is another technique to protect against crop failures. However, formal bank accounts or savings accounts in sub-Saharan countries are shown not to be attractive for most households, even if subsidized (Dupas et al., 2015). Major reasons for limited attractiveness and low active usage are extreme poverty ("too poor to save"), high transaction costs and coexistence with several alternative types of informal savings (Dupas et al., 2015). Monetary savings also suffer from a drop in purchasing power with extreme food price increases. Protection against the risk of crop of crop failure is possibly better addressed with formal insurance. Conventional insurance in agriculture has a bad record and proved infeasible due to severe problems of moral hazard and adverse selection, high monitoring costs and high administrative costs. Index insurance resolves these fundamental problems and is thereby considered an attractive and promising alternative for developing economy agricultural settings. During the last decades several practical applications, notably rainfall index insurance, have seen the light, often on a pilot basis. The potentially attractive properties of index insurance has also triggered a large research effort on impact and pitfalls of rainfall index insurance (Giné et al, 2008; Giné and Yang, 2009; Cole et al., 2013; Karlan et al, 2014; Dercon et al. 2014; Jensen et al., 2016; Ahmed et al., 2020). Unfortunately index insurance is not the silver bullet that is hoped for: willingness-to-pay and take-up appear to be notoriously low (Giné et al, 2008 Ahmed et al., 2020). Low take-up is attributed to a variety of causes like unfamiliarity with formal insurance, lack of understanding and poor information dissemination (Ahmed et al., 2020), the extent of basis risk (Giné et al, 2008; Dercon et al. 2014; Jensen et al., 2016), and the interaction with informal insurance arrangements (Dercon et al. 2014) or credit (Giné and Yang, 2009; Karlan et al, 2014; Ahmed et al., 2020). In this context livestock 
saving, another type of informal insurance, can also be expected to affect household demand for rainfall index insurance. Much research focuses on the impact of credit contingent with rainfall index insurance on technology adoption and investment in agriculture, rather than on food security (Karlan et al, 2014; Ahmed et al., 2020). Our measurements of staple food price increases during food shortages point at an essential requirement of indemnity claims of rainfall index insurance schemes (but also rainfall-insurance-backed social safety nets): these indemnity payments need to be defined in real terms, for example in $\mathrm{kg}$ of maize, corresponding with the loss of maize harvest, or its money equivalent at the price level of the moment the claims are made. This is likely to be a nasty hurdle for insurance contracts.

\section{Storage and storage policies}

In short, formal devices like bank or savings accounts, or index insurance schemes cannot effectively protect against the extreme staple food price increases that occur after droughts and crop failures. So what than offers adequate protection against food shortages? Savings in the form of storage of grain is a savings device that maintains its real value, even under extreme food shortages or food price increases. Evidence suggests that farmers often do not have access to appropriate storage technologies for staple foods (Aggarwal et al., 2018). Lack of adequate storage devices also could be a major reason for farmers to sell maize shortly after harvest. Alternatively, availability and use of good grain storage technologies is likely to have behavioral impacts on farmers (Aggarwal et al., 2018 25 ). If farm households are able to commit to store a quantity of grain equivalent to three months of staple food consumption after a normal or bumper harvest around 7 to 8 times out of 10 harvests - this would create sufficient protection against the following

\footnotetext{
${ }^{25}$ Aggarwal et al. (2018) document a variety of behavioral responses after the introduction of an adequate storage technology combined with communal granaries like reduced spoilage, less consumption, delayed sales, less reduction of stored grain through giving away, and less withdrawal because of storage outside the home.
} 
season possible crop failure ${ }^{26}$. Even storage for shorter periods is likely to generate major arbitrage gains (Burke et al., 2019). Implementing storage of individual farmer output at the village level appears to be effective as it enhances commitment and organization, and keep incentives close to beneficiaries, the farmers. Both shifting grain stocks to high price periods - either for home consumption after a crop failure, or to sell on the market - and sales of livestock to normal periods would both generate substantial arbitrage gains for farm households (Burke et al., 2019) ${ }^{27}$. A policy which promotes grain stocks at the household level by making crop storage bags available hermetically sealed storage bags, so-called Purdue Improved Crop Storage bags (PICS) - and to subsidize farmers' group level, village level or household level granaries recommends itself (Aggarwal et al. 2018). There may also be a role for governments to (partially) subsidize replenishment of maize after a food shortage. A combination of credit contingent with grain storage, implemented by commercial banks, could further enhance food security jointly with securing funds for risky investment (Basu and Wong, 2015; Aggarwal et al. 2018; Omotilewa et al., 2018; Channa et al, 2022).

\section{Summary and conclusion}

We measure to what extent food shortages affect the value of livestock savings. For this purpose we exploit monthly market prices of meat and maize in Malawi, for 72 locations (towns, villages and markets), for the period from 1991 to 2009. The empirical estimations offer convincing support for the claim that food shortages are associated with decreases in real meat prices, and

\footnotetext{
${ }^{26}$ Simultaneously grain storage provides sources for investment and technology adoption: If rains in the running season are sufficient and guarantee at least a normal end-of-season harvest, previous season stored grain can safely be liquidated.

${ }^{27}$ It should be noted that large general equilibrium effects reduce extreme price variation over the season (and thereby make livestock savings more useful), but also reduce the incentive to store grain.
} 
thereby in the value of livestock savings. The value of livestock - measured with the meat-maize terms of trade - decreases substantially during food shortages, with reductions averaged over villages, cities and towns, ranging from $56 \%$ to $73 \%$. The evidence is consistent with increased livestock sales during food shortages, but the drop in meat-maize terms of trade arises primarily due to maize price increases. Our results are robust for potential endogeneity of food shortages, for serial and spatial correlation and various other threats. Since the data do not allow to estimate the decrease in livestock value due to a lower body weight of livestock during food shortages, our estimates need to be interpreted as lower-bound estimates: the actual drop in livestock value is likely to be even larger. The reduction in the value of livestock occurs at the very moment livestock is sold on the market to purchase staple foods. Similar to produced staple foods, households systematically tend to sell low. Dampening price peaks in staple food prices during food shortages through diet diversification and irrigation and conservational cultivation techniques in agriculture will help to mitigate the drop in value of livestock savings. However, savings devices are needed that do not lose value during food shortages and thereby offer adequate protection. Such savings devices will generate large welfare gains and enhance economic growth. Most formal instruments are not suitable for this purpose. Storage of staple food appears a strategy with the best perspectives. 


\section{References}

Aggarwal, S., E. Francis and J. Robinson, 2018, 'Grain Today, Gain Tomorrow: Evidence from a Storage Experiment with Savings clubs in Kenya', Journal of Development Economics, $134,1-15$.

Ahmed, S., McIntosh, C., \& Sarris, A., 2020, 'The Impact of Commercial Rainfall Index Insurance: Experimental Evidence from Ethiopia.' American Journal of Agricultural Economics, 102, 4, 1154-1176.

Barrett, C.B., F.Chabari, D.Bailey, P.D.Little and D.L.Coppock, 2003, 'Livestock Pricing in Northern Keynean Rangelands', Journal of African Economies, 12, 2, 127-155.

Basu, K and M.Wong, 2015, 'Evaluating Seasonal Food Storage and Credit Programs in East Indonesia', Journal of Development Economics, 115, 200-216.

Burke, M., L. Falcao Bergquist, and E. Miguel, 2019, 'Sell Low and Buy High: Arbitrage and Local Price Effects in Kenyan Markets', The Quarterly Journal of Economics, 134, 2, 785 842.

Cliff, A.D. and J.K. Ord, 1983, Spatial Processes: Models and applications. London: Pion.

Channa, H, J. Ricker-Gilbert, S. Feleke, T. Abdoulaye, 2022, 'Overcoming smallholder farmers' post-harvest constraints through harvest loans and storage technology: Insights from a randomized controlled trial in Tanzania', Journal of Development Economics, forthcoming.

Cole, S.A., X. Giné, J.Tobacman, P.B.Topalova and R.M. Vickery, 2013, 'Barriers to Household Risk Management: Evidence from India', American Economic Journal: Applied Economics, 5, 1, 104-135.

Dercon, S., 1998, 'Wealth, Risk and Activity Choice: Cattle in Western Tanzania', Journal of 
Development Economics, 55, 1-42.

Dercon, S., 2002, 'Income risk, coping strategies, and safety nets', The World Bank Research Observer, 17, 2, 141-166.

Dercon, S., R. Vargas Hill, D. Clarke, I. Outes-Leona, A. S. Taffesse, 2014, 'Offering rainfall insurance to informal insurance groups: Evidence from afield experiment in Ethiopia', Journal of Development Economics, 106, 132-143.

Driscoll, J.C and A.C.Kraay, 1998, 'Consistent Covariance Matrix Estimation With Spatially Dependent Panel Data', Review of Economics and Statistics, 80, 4, 549-560.

Dupas, P., D. Karlan, J. Robinson and D.Ubfal, 2018, 'Banking the Unbanked? Evidence from Three Countries', American Economic Journal: Applied Economics, 10, 2, 257-297.

Elbers, C., J.W. Gunning and B. Kinsey, 2007, 'Growth and Risk: Methodology and Micro Evidence', The World Bank Economic Review, 21, 1, 2007, 1-20.

Fafchamps, M., C. Udry, and K. Czukas, 1998, 'Drought and saving in West Africa: Are livestock a buffer stock?' Journal of Development Economics, 55, 2, 273-305.

Fafchamps, M., E.Gabre-Madhin and B.Minten, 2005, 'Increasing returns and market efficiency in agricultural trade', Journal of Development Economics, 78, 406-442.

Gilbert, C.L., L. Christiaensen and J. Kaminiski, 2017, 'Food price seasonality in Africa: Measurement and extent', Food Policy, 67, 119-132.

Giné, X., R.Townsend and J.Vickery, 2008, 'Patterns of Rainfall Insurance Participation in Rural India’, World Bank Economic Review, 22, 3, 539-566.

Giné, X. and D.Yang, 2009, 'Insurance, Credit, and Technology Adoption: Field Experimental Evidence from Malawi', Journal of Development Economics, 89, 1-11. 
Hänke, H and J. Barkmann, 2017, 'Insurance Function of Livestock: Farmers’ Coping Capacity with Crop Failure in South-Western Madagascar' World Development, 96, 264-275;

Jensen, N.D., C.B. Barrett, A.G. Mude, 2016, 'Index Insurance Quality and Basis Risk:

Evidence from Northern Kenya', American Journal of Agricultural Economics, 98, 5, $1450-1469$.

Kaminski, J., L. Christiaensen and C.L.Gilbert, 2016, 'Seasonality in Local Food Prices and Consumption: Evidence from Tanzania', Oxford Economic Papers, 68, 3, 736-757.

Karlan, D., R. Osei, I. Osei-Akoto and C. Udry, 2014, 'Agricultural Decisions after Relaxing Credit and Risk Constraints', Quarterly Journal of Economics, 129, 2, 597-652.

Kazianga, H. and C.Udry, 2006, 'Consumption smoothing? Livestock, insurance and drought in rural Burkina Faso', Journal of Development Economics, 79, 2, 413-446.

Kinsey, B., K. Burger and J.W. Gunning, 1998, 'Coping with drought in Zimbabwe: Survey evidence on responses of rural households to risk', World Development, 26, 1, 89-110.

Mogues, T., 2011, 'Shocks and asset dynamics in Ethiopia', Economic Development and Cultural Change, 60, 1, 91-120.

Moran, P. A. P., 1950, 'Notes on continuous stochastic phenomena', Biometrika, 37, 17-23.

Omotilewa, O.J., J. Ricker-Gilbert, J.H. Ainembabazi and G. Shively, 2018, 'Does improved storage technology promote modern input use and food security? Evidence from a randomized trial in Uganda, Journal of Development Economics, 135, 196-198.

Owens, T. and J. Hoddinott, 2003, 'Ex-Ante Actions and Ex-Post Public Responses to Drought Shocks: Evidence and Simulations from Zimbabwe', World Development, 31, 7, 12391255 .

Rosenzweig, M. R. and K. I. Wolpin, 1993, 'Credit market constraints, consumption smoothing, 
and the accumulation of durable production assets in low-income countries: Investments in bullocks in India', Journal of Political Economy, 101, 2, 223-244.

Smale, M., 1995, "Maize is life": Malawi's delayed Green Revolution, World Development, 23, $5,819-831$

Turner, M. and T.O.Williams, 2002, 'Livestock Market Dynamics and Local Vulnerabilities in the Sahel', World Development, 30, 4, 683-705.

Zant, W., 2012, 'The Economics of Food Aid under Subsistence Farming with an Application to Malawi’, Food Policy, 37, 1, 124-141.

Zant, W, 2013, How Is the Liberalization of Food Markets Progressing? Market Integration and Transaction Costs in Subsistence Economies', The World Bank Economic Review, 27, 1, $28-54$.

Zant, W., 2020, 'If smallholder farmers have access to the world market: the case of tobacco marketing in Malawi', European Review of Agricultural Economics, 47,4, 1402-1437. 


\section{Appendix}

Figure A1a Tropical Livestock Units per household, by ADD and year (all types: upper panel; without cattle: lower panel)
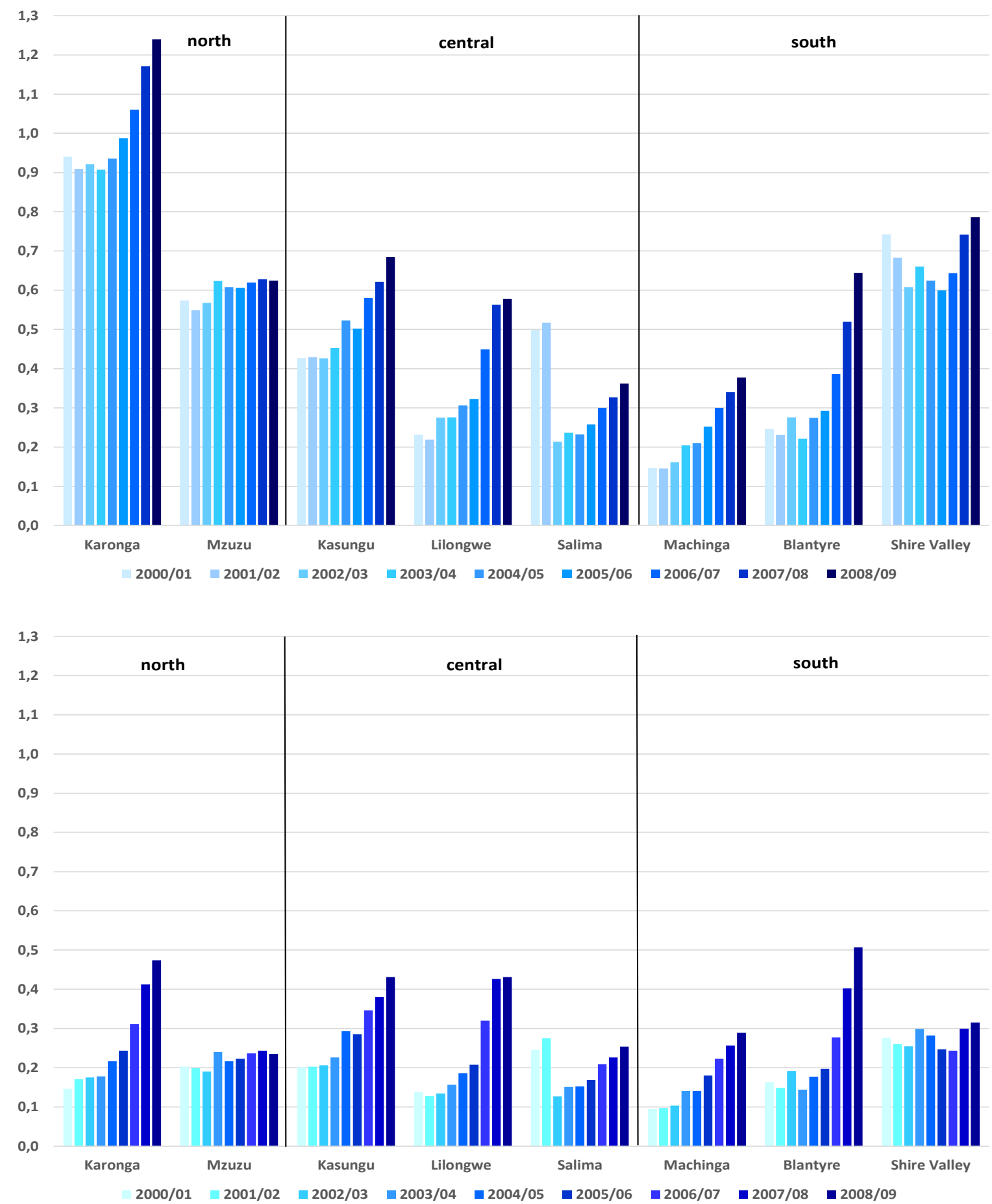

Source: Ministry of Agriculture, Lilongwe, Malawi. 
Figure A1b Livestock by type, ADD and year (units per household)
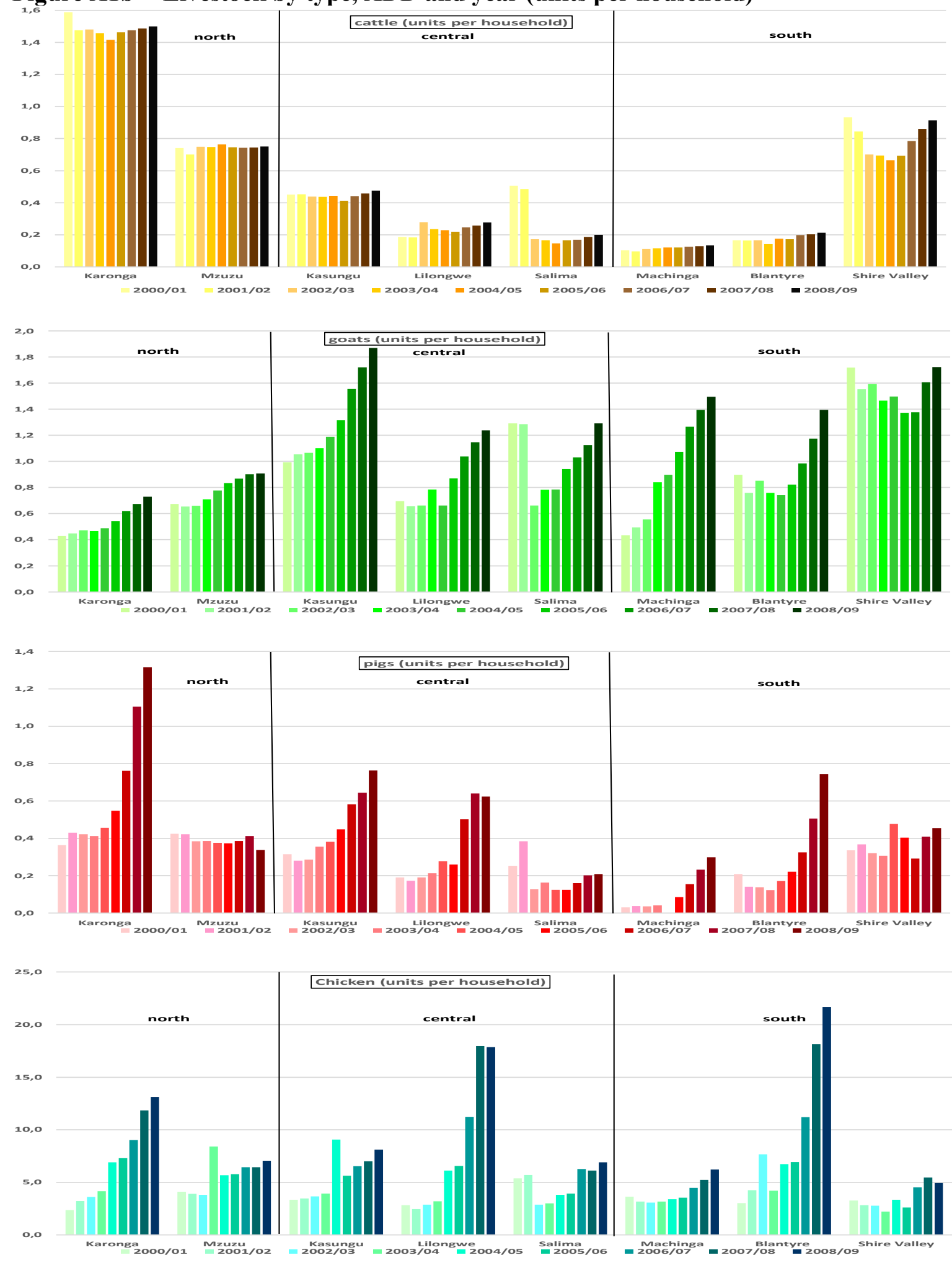

Source: Ministry of Agriculture, Lilongwe, Malawi. 
Figure A2 Price development and price data availability
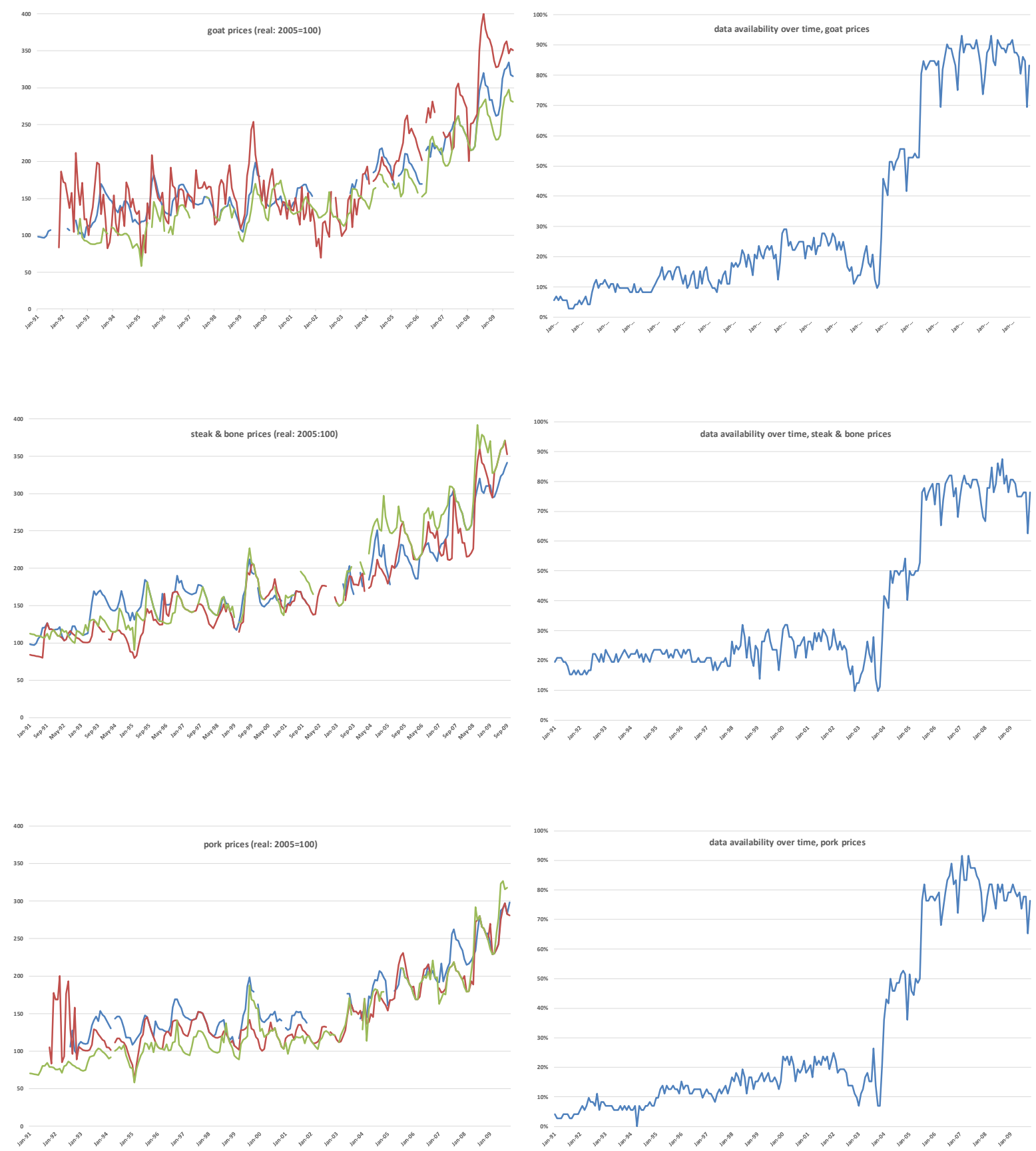

Note to figures: Price developments (left panels) show staple food and meat prices in 2005 constant prices, deflated with the national consumer price index, for three selected markets for which many observations are available. Data availability (right panels) shows the share of locations / markets (72 in total) for which price data are available. Source: Agro-Economic Survey, Ministry of Agriculture and Food Security, Government of Malawi. 
Figure A2 Price development and price data availability (continued)
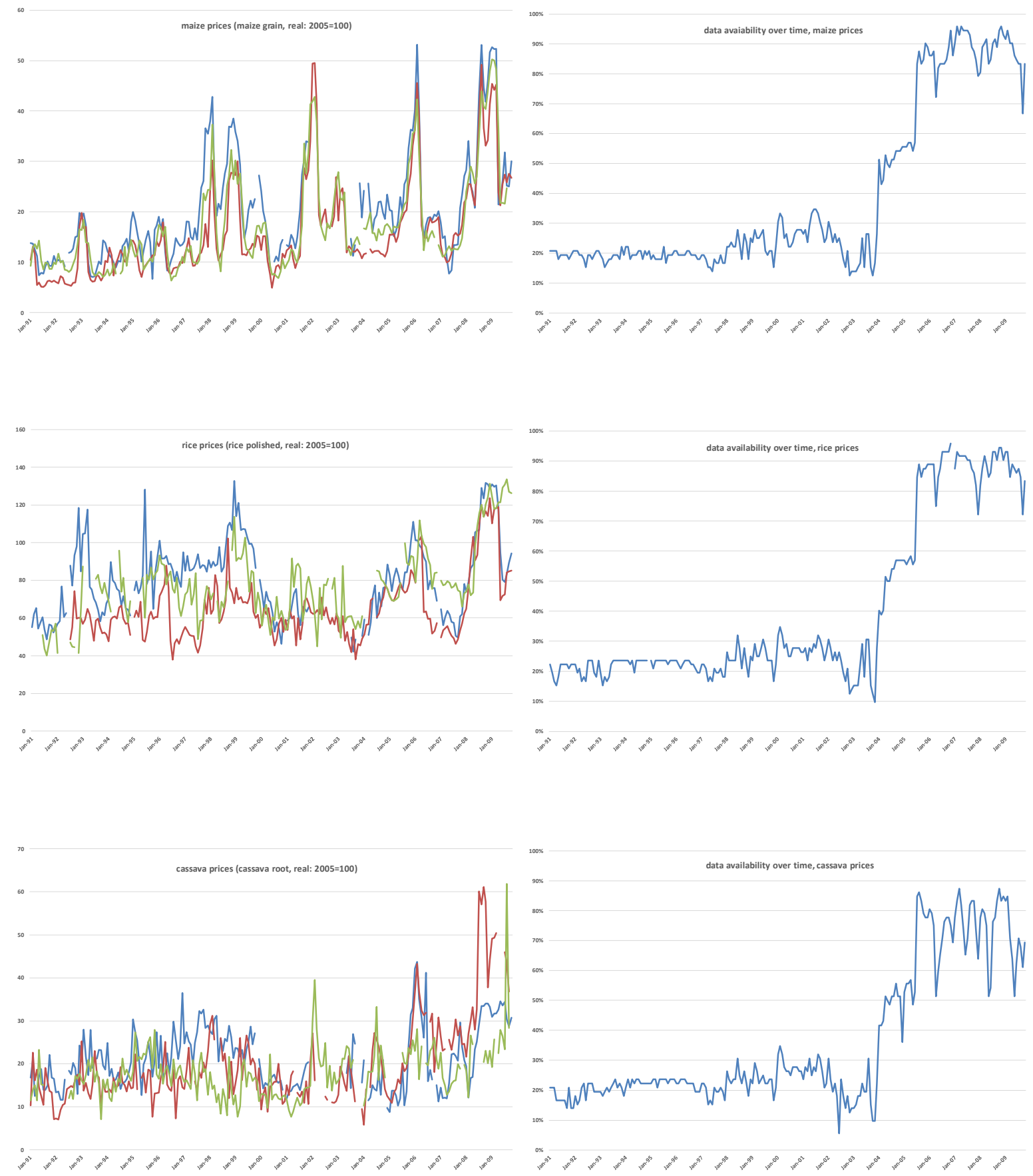

Note to figures: Price developments (left panels) show staple food and meat prices in 2005 constant prices, deflated with the national consumer price index, for three selected markets for which many observations are available. Data availability (right panels) shows the share of locations / markets (72 in total) for which price data are available. Source: Agro-Economic Survey, Ministry of Agriculture and Food Security, Government of Malawi. 
Figure A3 Markets in Malawi

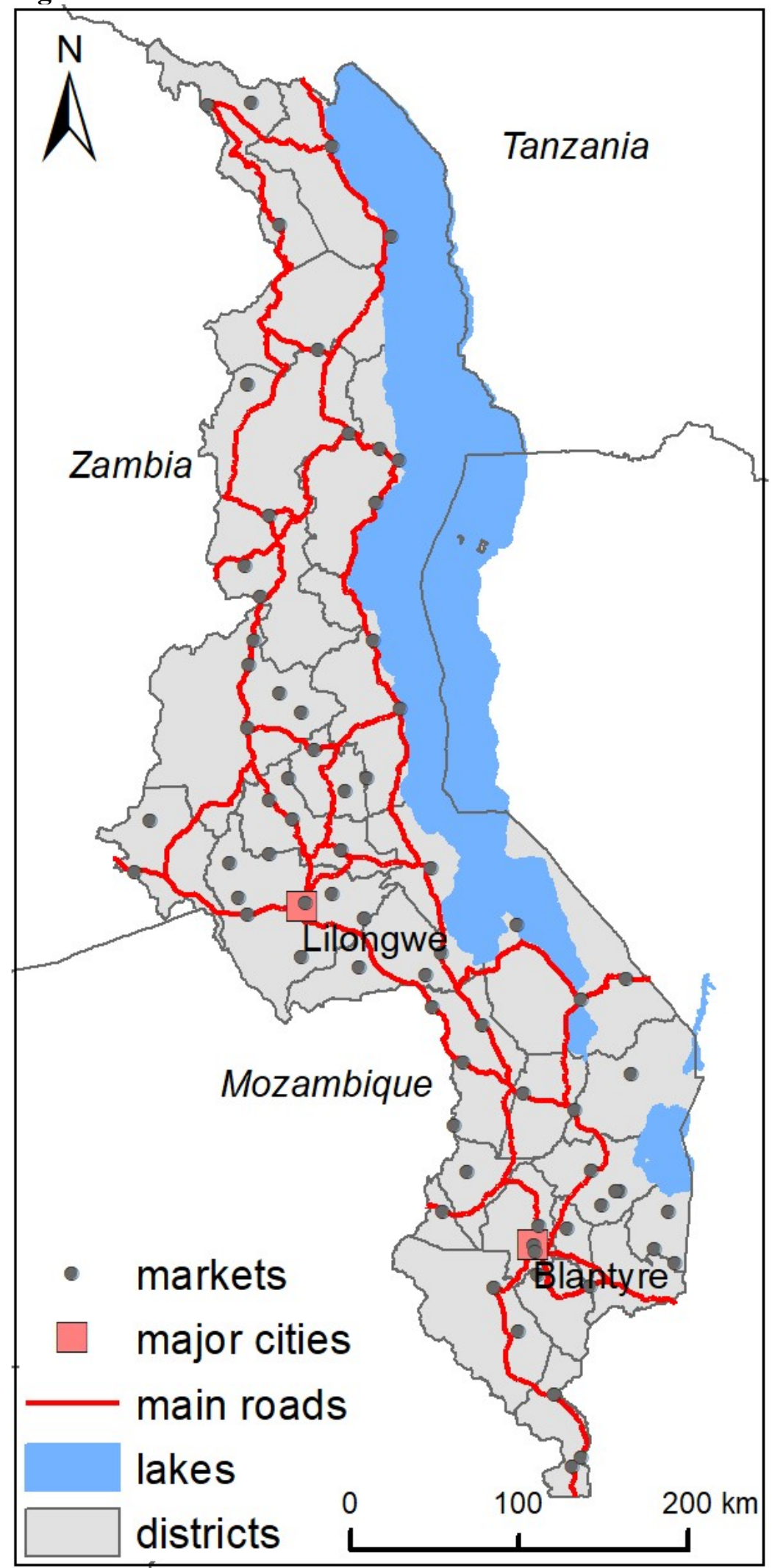


Figure A4 Last season maize production relative to current season maize requirements

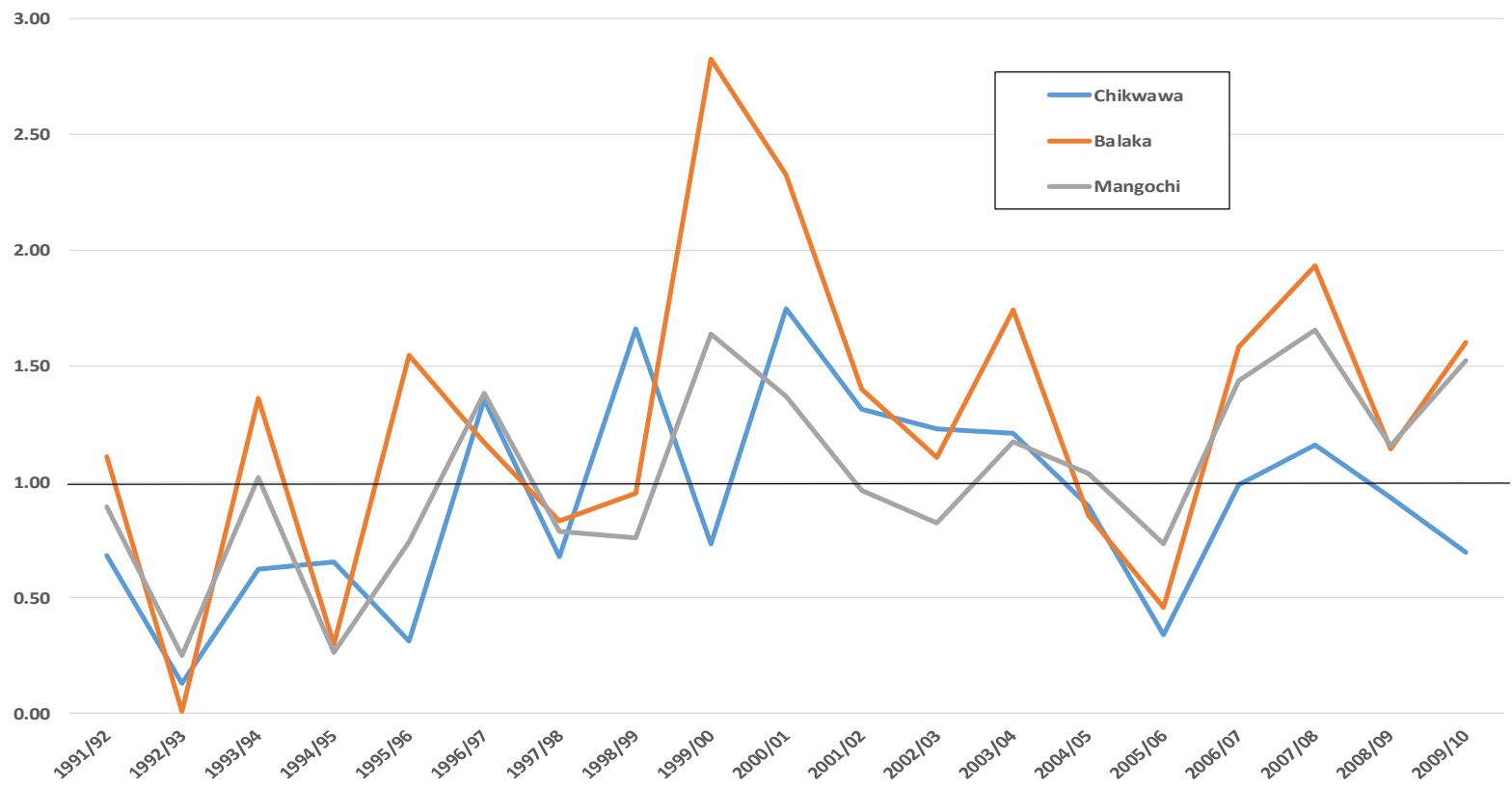

Note to figure: Calculations based on data from National Statistical Office and Agro-Economic Survey, Ministry of Agriculture and Food Security, Government of Malawi; the selection of districts is arbitrary.

Figure A5a Meat-staple food terms of trade: goat meat- cassava, Malawi, 2005-2006

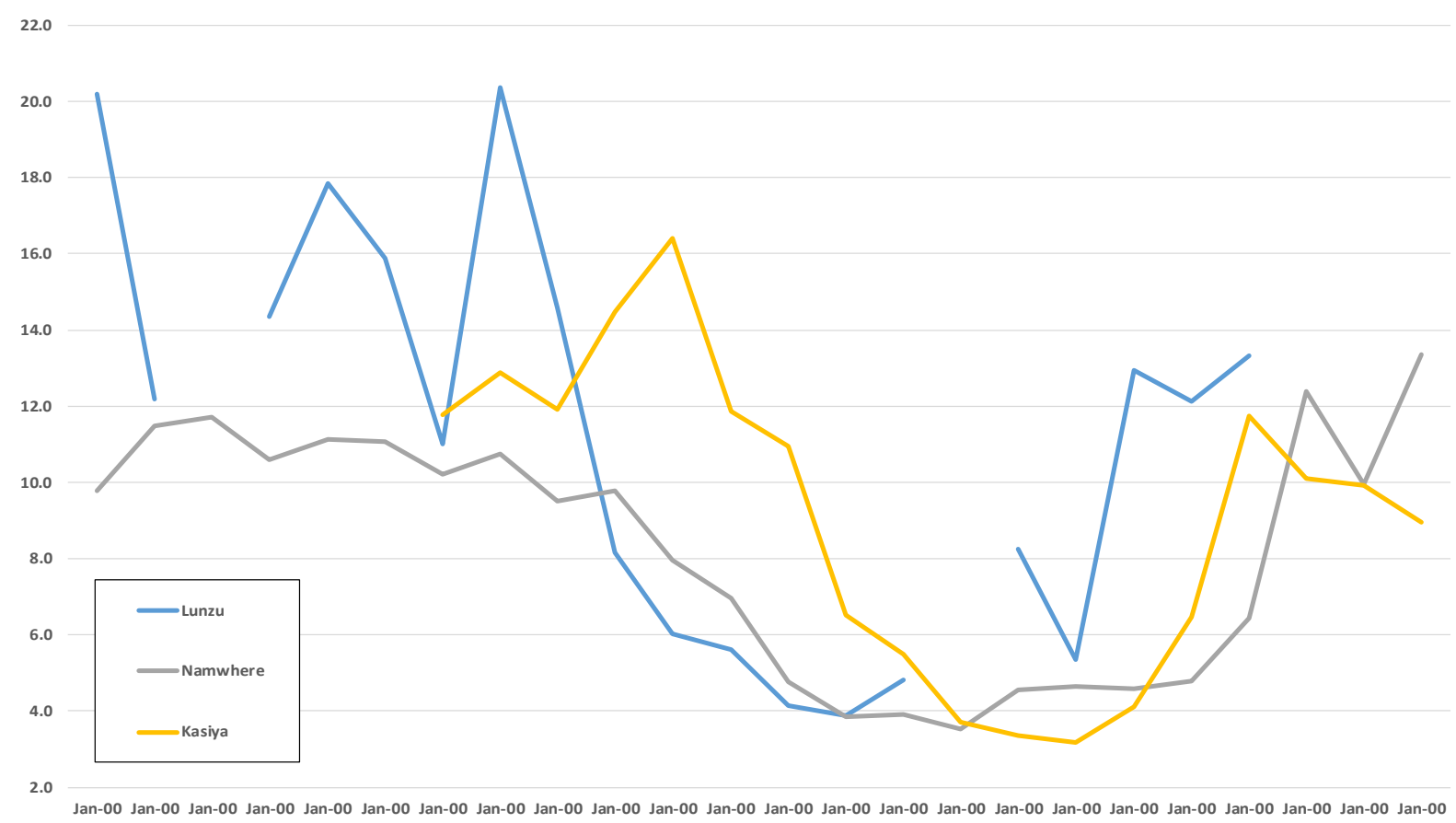

Note to figure: figure shows $\mathrm{p}_{\text {meat }} / \mathrm{p}_{\text {staple food }}$ S Source: calculations based on data from Agro-Economic Survey, Ministry of Agriculture and Food Security. 
Figure A5b Meat-staple food terms of trade: meat-beans, Uganda, 2011

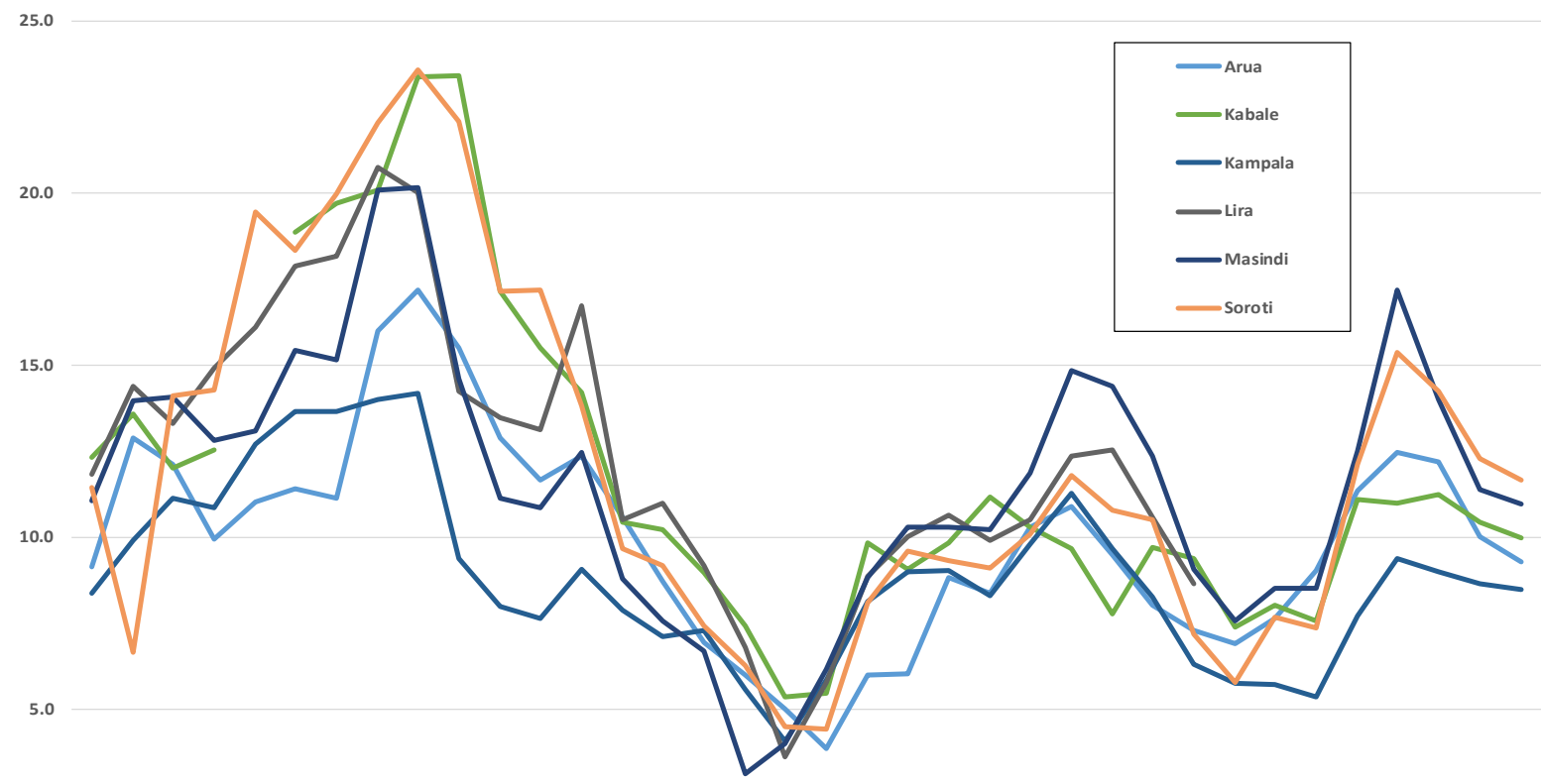

0.0 (2) Note to figure: figure shows $p_{\text {meat }} /$ pstaple food; $_{\text {; }}$ Source: calculations based on data from ASARECA-ReSAKKS.

Figure A5c Meat-staple food terms of trade: meat-maize, Uganda, 2008

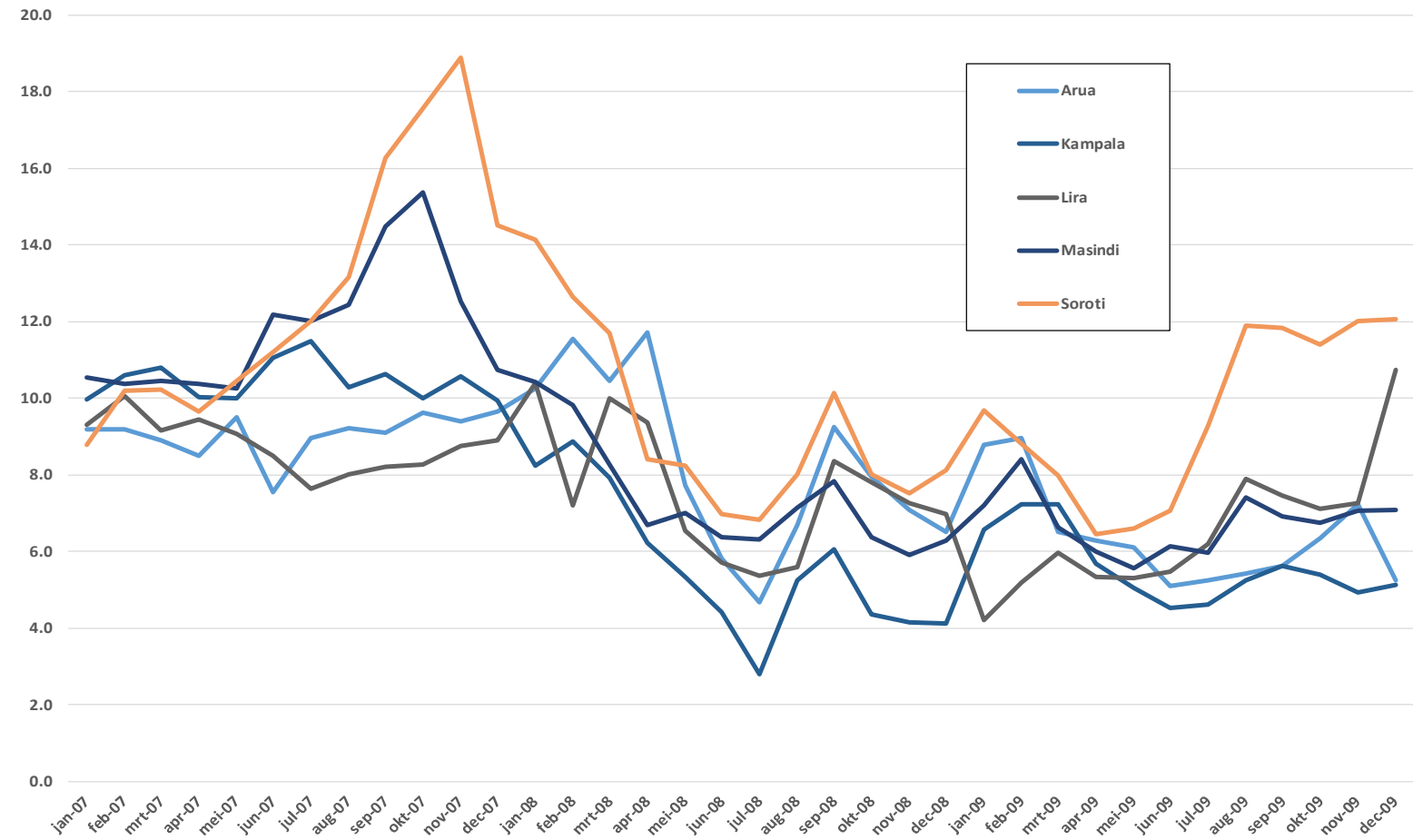

Note to figure: figure shows $\mathrm{p}_{\text {meat }} / \mathrm{p}_{\text {staple food; }}$ Source: calculations based on data from ASARECA-ReSAKKS 
Figure ADd Meat-staple food terms of trade: meat-beans, Uganda, 2005-2006

16.0

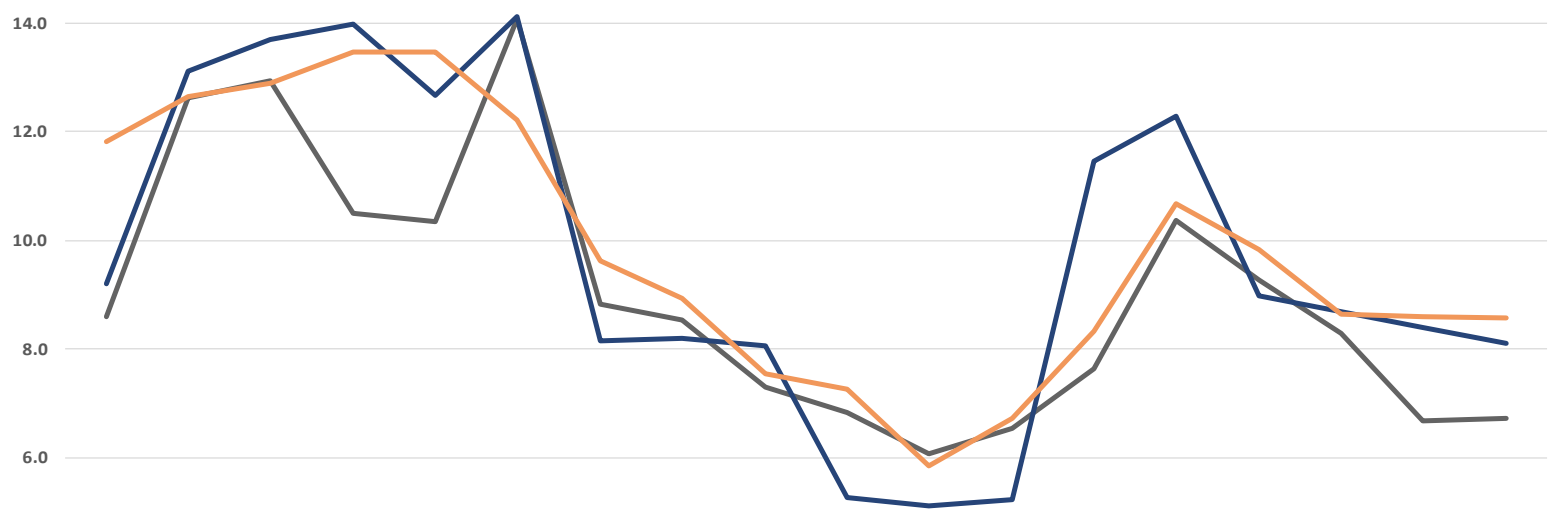

4.0

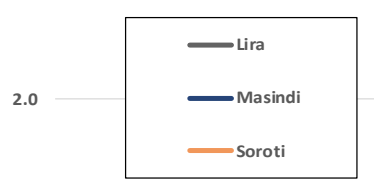

0.0

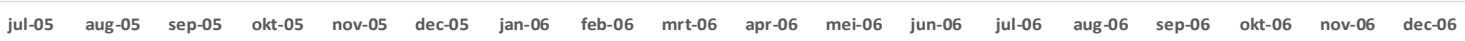

Note to figure: figure shows $\mathrm{p}_{\text {meat }} / \mathrm{p}_{\text {staple food; }}$ Source: calculations based on data from ASARECA-ReSAKKS

Figure Abe Meat-staple food terms of trade: meat-maize, Kenya, 2011

10.0

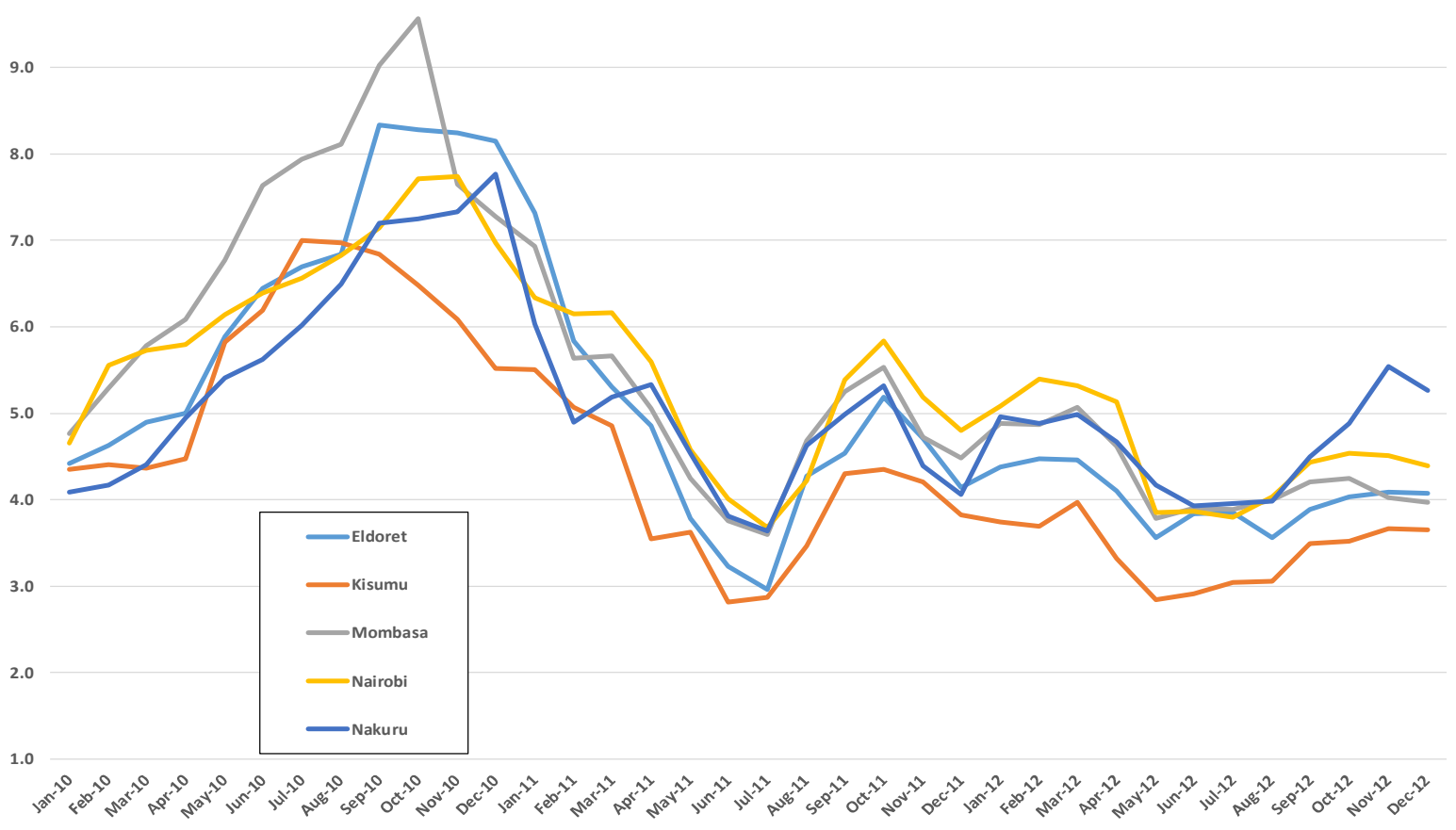

Note to figure: figure shows $\mathrm{p}_{\text {meat }} / \mathrm{p}_{\text {staple food; }}$ Source: calculations based on data from ASARECA-ReSAKKS

45 
Figure Af Meat-staple food terms of trade: goats-various, Baidoa, Somalia, 2011

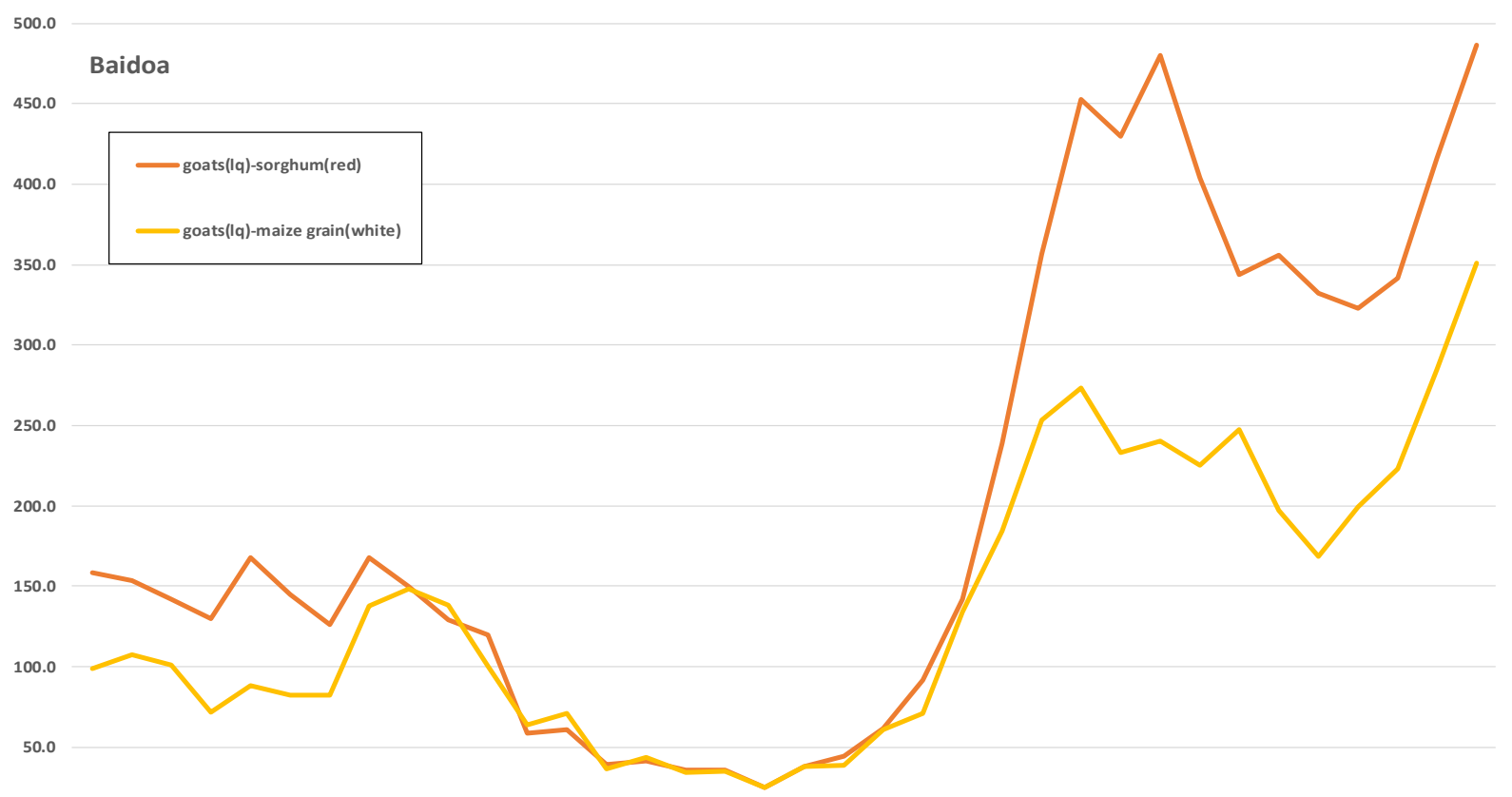

0.0

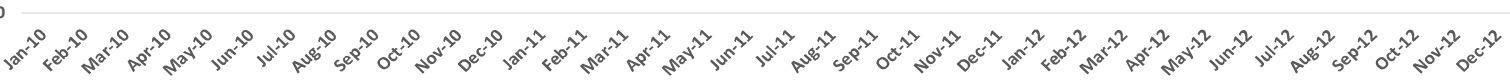

Note to figure: figure shows $\mathrm{p}_{\text {meat }} / \mathrm{p}_{\text {staple food; }}$ Source: calculations based on data from FEWSNET

Figure A5g Meat-staple food terms of trade: goats-various, Burao, Erigavo, Somalia, 2016

120.0

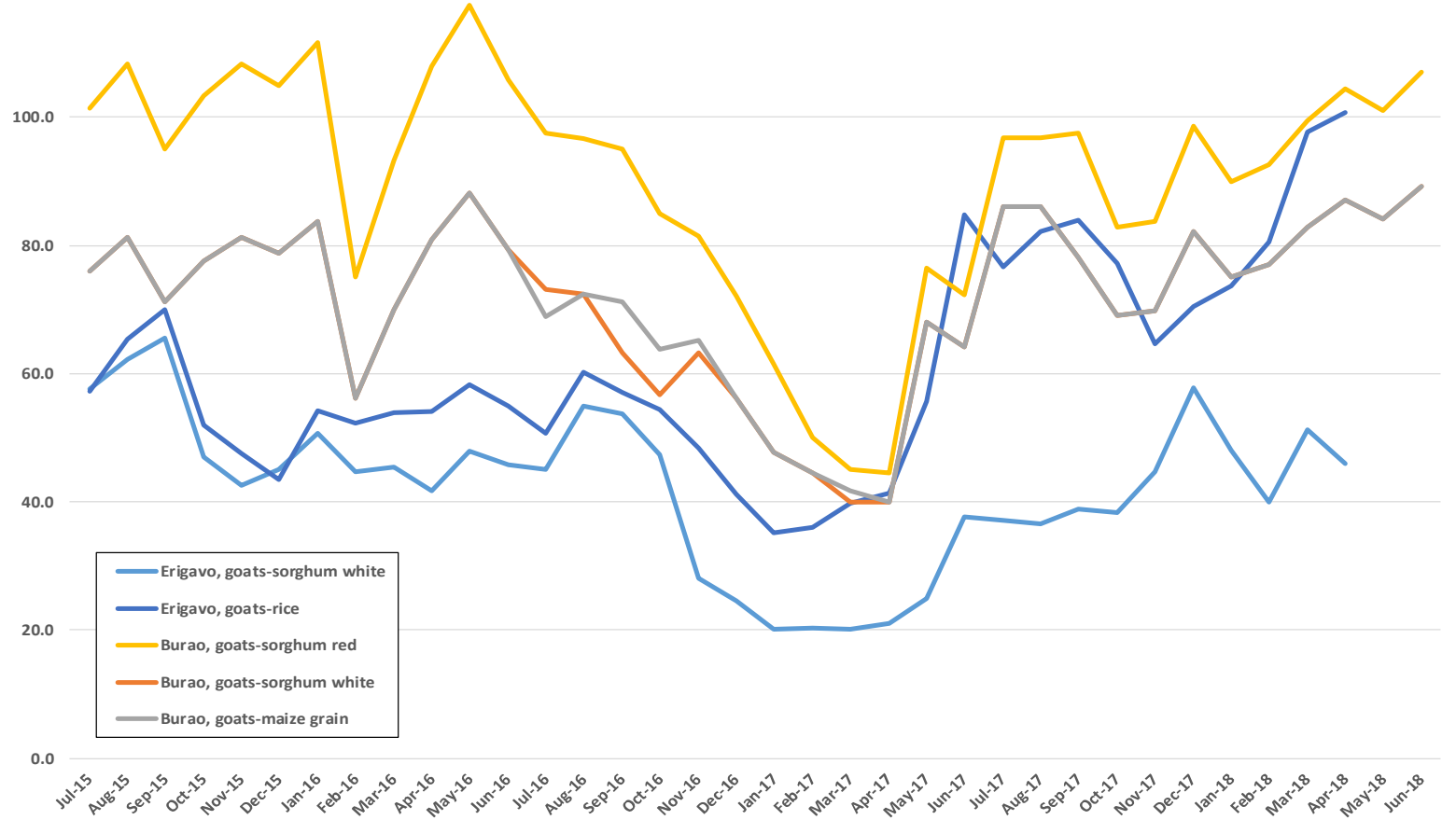

Note to figure: figure shows $\mathrm{p}_{\text {meat }} / \mathrm{p}_{\text {staple food; }}$ Source: calculations based on data from FEWSNET

46 
Table A1 Annual rainfall from April to March, by district (Rural Development Project)

\begin{tabular}{|c|c|c|c|c|c|c|c|c|c|c|c|c|c|c|c|c|c|c|c|c|c|c|c|c|}
\hline gion & $A D D$ & district & & $1989-90$ & $1990-91$ & 1991-92 & $1992-93$ & $1993-94$ & $1994-95$ & $1995-96$ & $1996-97$ & $1997-98$ & $1998-99$ & 1999-2000 & 2000-01 & 2001-02 & 2002-03 & 2003-04 & $2004-05$ & 2005-06 & $2006-07$ & $2007-08$ & 2008-09 & 2009 \\
\hline & Karonga & itipa & 1 & 1166.3 & 862.7 & 1005.9 & 783.9 & 611.9 & 907.6 & 1010.7 & 863.8 & 1362.9 & 847.6 & 646.6 & 976.6 & 878.7 & 939.3 & 938.7 & 1079.0 & 969.9 & 1021.1 & 808.8 & 898.2 & \\
\hline north & Karonga & aronga & 2 & 779.5 & 828.6 & 908.0 & 872.4 & 481.9 & 740.1 & 1047.1 & 484.1 & 1332.5 & 889.2 & 745.4 & 1168.8 & 1269.0 & 918.8 & 1189.2 & 1081.0 & 1083.5 & 819.1 & 898.1 & 1029.4 & 922.6 \\
\hline orth & uzu & Rumphi & 3 & 720.5 & 2.2 & & 676.9 & 487.3 & 609.7 & 744.0 & 677.3 & 595.1 & 589.2 & 471.7 & 660.3 & 793.5 & 729.3 & 755.0 & 689.3 & 524.3 & 781.0 & 748.0 & 768.3 & 820.3 \\
\hline rth & uzu & mba & 4 & 1004.4 & 825.4 & 670.7 & 9.9 & 721.3 & 790.3 & 931.1 & 683.4 & 806.3 & 952.9 & 701.8 & 1026.4 & 916.5 & 874.9 & 940.3 & 891.8 & 668.8 & 940.8 & 801.9 & 787.6 & 775.2 \\
\hline north & uzu & Nkhatabal & 5 & 1666.2 & 1552.3 & 991.1 & 1253.8 & 1083.8 & 1404.9 & 1724.0 & 1181.9 & 1590.9 & 2066.3 & 1154.0 & 1520.8 & 1652.4 & 1562.3 & 1604.9 & 1062.7 & 1386.3 & 1338.4 & 1441.4 & 1328.3 & 1485.1 \\
\hline ntral & sungu & Kasungu & 6 & 919.3 & 803.7 & 554.1 & 880.2 & 836.9 & 537.1 & 938.7 & 885.7 & 915.3 & 869.3 & 612.2 & 936.5 & 669.5 & 1061.0 & 835.6 & 918.3 & 611.5 & 1135.1 & 657.6 & 720.6 & 773.8 \\
\hline ntral & sungu & hinji & 11 & 1051.0 & 65.7 & 673.0 & 1115.0 & 806.1 & 539.0 & 862.6 & 851.7 & 1338.6 & 1433.2 & 825.4 & 1705.4 & 869.5 & 1173.3 & 840.3 & 691.1 & 1454.7 & 1219.8 & 1129.0 & 1183.4 & 1019.8 \\
\hline tral & & & 8 & & & & & & 655.7 & & & .9 & & & 2.0 & 144 & & 688.1 & 1.9 & 8 & 103 & 7.8 & 706.5 & 1113.5 \\
\hline ntral & ungu & wa & 9 & 1.6 & 728.1 & 622.6 & 885.0 & 581.4 & 658.1 & 975.9 & 782.5 & 1136.8 & 923.5 & 682.1 & 1305.1 & 861.4 & 1037.2 & 666.6 & 797.9 & 768.8 & 924.4 & 989.1 & 740.5 & 1004.1 \\
\hline ntral & ima & $\mathrm{ma}$ & 10 & 1036.3 & 1042.1 & 1002.8 & 1297.7 & 828.7 & 490.5 & 1124.9 & 1196.0 & 1621.5 & 1194.2 & 22.6 & 1386.8 & 1467.6 & 1566.9 & 1059.3 & 883.9 & 1570.8 & 1313.3 & 1236.9 & 1235.7 & 967.5 \\
\hline central & Salima & Nkhotako & 1 & & 1305.4 & 992.7 & 2052.8 & 01.6 & 1042.8 & 88.3 & & .7 & & 558.7 & 1697.8 & 87.4 & 1190.0 & 1277.4 & 1261.6 & 1332.9 & 1287.3 & 1520.4 & 2049.7 & 884.3 \\
\hline ntral & ngwe & Lilongwe & 12 & 1025.0 & 708.6 & 652.4 & 940.1 & 625.1 & 536.0 & 1048.1 & 837.0 & 1078.4 & 1171.4 & 678.0 & 979.7 & 882.4 & 1077.1 & 737.9 & 811.2 & 780.3 & 924.7 & 979.6 & 830.3 & 725.3 \\
\hline central & Lilongwe & Ntcheu & 15 & & 1019.2 & 519.9 & 971.8 & 790.8 & 917.1 & 922.5 & 55.0 & 1.5 & 20.3 & 1.3 & 888.4 & 960.1 & 132 & 741.9 & 846.2 & 1051.0 & 1029.8 & 1050.4 & 84.9 & 912.4 \\
\hline iuth & Machinga & Mangochi & 14 & 762.2 & 2.9 & 585.3 & 883.4 & 414.7 & 422.7 & 873.0 & 1306.1 & 721.6 & 9 & 766.9 & 1236.1 & 854. & 1109.5 & 561.3 & 744.4 & 900.9 & 1086.7 & 928.5 & 880.9 & 851.0 \\
\hline 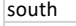 & M & Maching & 16 & & & 641.5 & 956.5 & 542.9 & 614.0 & 1029.8 & 1541.5 & 8 & & 76 & 1325.2 & 896. & 1076.9 & t & 739.9 & 1040.6 & 1123.6 & 936.5 & 52.7 & 796.8 \\
\hline south & Machinga & Balaka & 17 & 706.0 & 933.5 & & 772.4 & 675.0 & 871.0 & 738.2 & 1350.3 & 722.2 & 1099.4 & 803.0 & 927.5 & 907.9 & 689.9 & 969.0 & 487.9 & 1047.8 & 941.6 & 676.4 & 667.0 & 464.1 \\
\hline south & Machin & Zomba & 18 & 3 & 24 & 684.4 & 979.2 & .7 & 695.3 & 1126.7 & 1399.3 & 1058.5 & 3.8 & 0.3 & 1420.3 & 931.4 & 1048.5 & 813.9 & 781.1 & 1189.1 & 1091.8 & 1072.1 & 965.1 & 932.9 \\
\hline uth & tyre & Phalombe & 24 & 13 & 1236.4 & 849.1 & 1316.0 & 882.1 & 997.4 & 1378.7 & 1526.3 & 1374.9 & 1547.9 & 1044.8 & 1663.7 & 1223.4 & 1346.5 & 93 & 1018.9 & 9.2 & 1266.2 & 184.0 & 1266.0 & 1123.0 \\
\hline south & yre & 1 & 19 & 973.5 & 2.3 & Af & 9 & 04.5 & 1315.7 & 675.2 & 78.9 & 0 & & 829.9 & 1.3 & 1062. & 988.5 & & 2.4 & 3.9 & 805 & 339.0 & 657.0 & 616.0 \\
\hline south & & N & 20 & & & & & & 112 & & & 1233 & & & .7 & 10 & 20 & & 4.6 & 8.4 & 7.8 & 857.3 & 0 & 671.8 \\
\hline outh & ntyre & $F_{2}$ & 21 & 821.4 & 851.4 & 589 & 932.9 & 7 & 67 & 1015.9 & 1414.7 & 106 & 1179.5 & 860.4 & 1304.1 & 95 & 75.3 & 590 & 5.4 & 64.5 & 268.1 & 51.5 & 3.9 & 40.3 \\
\hline th & & zult & 22 & & 82 & & 836.1 & 762.0 & 794. & 968.6 & 1296.4 & 1073.1 & & 862.3 & 1379.2 & 859 . & 82 & 64 & 529.8 & 8.6 & B48. & 873.0 & 32.0 & 3.0 \\
\hline south & & & 23 & & 105 & 666.8 & 2.5 & & 113 & & & & & & & & 5.9 & 938.8 & 3.6 & 5.9 & 603. & 76.9 & 324.6 & 1252.3 \\
\hline & & & 25 & 55.1 & 90 & 716.6 & 1224.3 & 759. & $908 . \varepsilon$ & 1355.1 & 1609.1 & 1370.7 & 1727.4 & 885.4 & 1453.4 & 1580.6 & 085.6 & 834. & 9.7 & 1346.4 & 258.3 & 267.3 & 145.8 & 1108.1 \\
\hline
\end{tabular}

Note to Table: the darker shades indicate increasingly lower rainfall levels relative to minimum rainfall levels required for vegetative growth (around $700 \mathrm{~mm}$ per season). 
Table A2 Regions, ADDs, RDP and markets

\begin{tabular}{|c|c|c|c|c|c|c|c|}
\hline Region & ADD & RDP & Market & region & ADD & RDP & Market \\
\hline North & Karonga & Chitipa & Chitipa & central & Lilongwe & Lilongwe & Nkhoma \\
\hline North & Karonga & Chitipa & Misuku & central & Lilongwe & Lilongwe & Nsundwe \\
\hline North & Karonga & Chitipa & Nthalire & central & Lilongwe & Ntcheu & Lizulu \\
\hline North & Karonga & Karonga & Chilumba & central & Lilongwe & Ntcheu & Ntcheu \\
\hline North & Karonga & Karonga & Karonga & central & Lilongwe & Ntcheu & Sharpevalley \\
\hline North & Mzuzu & Mzimba & Embangweni & central & Lilongwe & Ntcheu & Tsangano_To \\
\hline North & Mzuzu & Mzimba & Jenda & central & Salima & Nkhotakota & Dwangwa \\
\hline North & Mzuzu & Mzimba & Mzimba & central & Salima & Nkhotakota & Mwansambo \\
\hline North & Mzuzu & Mzimba & Mzuzu & central & Salima & Nkhotakota & Nkhotakota \\
\hline North & Mzuzu & NkhataBay & Chintheche & central & Salima & Salima & Salima \\
\hline North & Mzuzu & NkhataBay & Mpamba & south & Blantyre & Blantyre & Limbe \\
\hline North & Mzuzu & NkhataBay & Nkhatabay & south & Blantyre & Blantyre & Lunzu \\
\hline North & Mzuzu & Rumphi & Hewe & south & Blantyre & Blantyre & Ntonda \\
\hline North & Mzuzu & Rumphi & Rumphi & south & Blantyre & Chiradzulu & Chiradzulu \\
\hline Central & Kasungu & Dowa & Bowe & south & Blantyre & Mulanje & Muloza \\
\hline Central & Kasungu & Dowa & Dowa & south & Blantyre & Mwanza & Mwanza \\
\hline Central & Kasungu & Dowa & Madisi & south & Blantyre & Mwanza & Neno \\
\hline Central & Kasungu & Dowa & Mponela & south & Blantyre & Phalombe & Migowi \\
\hline Central & Kasungu & Kasungu & Chamama & south & Blantyre & Phalombe & Phalombe \\
\hline Central & Kasungu & Kasungu & Chatoloma & south & Blantyre & Thyolo & Bvumbwe \\
\hline Central & Kasungu & Kasungu & Kasungu & south & Blantyre & Thyolo & Luchenza \\
\hline Central & Kasungu & Kasungu & Nkhamenya & south & Machinga & Balaka & Balaka \\
\hline Central & Kasungu & Kasungu & Santhe & south & Machinga & Machinga & Liwonde \\
\hline Central & Kasungu & Mchinji & Mchinji & south & Machinga & Machinga & Ntaja \\
\hline Central & Kasungu & Mchinji & Mkanda & south & Machinga & Mangochi & Mangochi \\
\hline Central & Kasungu & Ntchisi & Malomo & south & Machinga & Mangochi & Monkeybay \\
\hline Central & Kasungu & Ntchisi & Ntchisi & south & Machinga & Mangochi & Namwera \\
\hline Central & Lilongwe & Dedza & Bembeke & south & Machinga & Zomba & Jali \\
\hline Central & Lilongwe & Dedza & Mtakataka & south & Machinga & Zomba & Mayaka \\
\hline Central & Lilongwe & Dedza & Thete & south & Machinga & Zomba & Thondwe \\
\hline Central & Lilongwe & Lilongwe & Chimbiya & south & Machinga & Zomba & Zomba \\
\hline Central & Lilongwe & Lilongwe & Kasiya & south & ShireValley & Chikwawa & Chikwawa \\
\hline Central & Lilongwe & Lilongwe & Lilongwe & south & ShireValley & Chikwawa & Nchalo \\
\hline Central & Lilongwe & Lilongwe & Mitundu & south & ShireValley & Chikwawa & Ngabu \\
\hline Central & Lilongwe & Lilongwe & Nanjiri & south & ShireValley & Nsanje & Bangula \\
\hline Central & Lilongwe & Lilongwe & Nambuma & south & ShireValley & Nsanje & Nsanje \\
\hline
\end{tabular}




\section{Additional estimation output}

\section{Regional and rural-urban variation}

Table A3a Meat-Maize Price Gaps versus Maize Abundance-Scarcity, 1992-2009, north

\begin{tabular}{|c|c|c|c|}
\hline & (1) & (2) & (3) \\
\hline dependent variable: & $\ln \left(\right.$ gap $^{\text {goat }} /$ gap $\left.^{\text {maize }}\right)$ & $\ln \left(\right.$ gap $\left.^{\text {goat }}\right)$ & $\ln \left(\right.$ gap $\left.^{\text {maize }}\right)$ \\
\hline 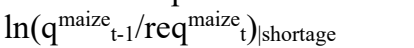 & $0.808^{* *}(0.327)$ & $0.298^{*}(0.158)$ & $-0.268^{* *}(0.124)$ \\
\hline$\left.\ln \left(\mathrm{q}^{\text {maize }} \mathrm{t-1} / \mathrm{req}^{\text {maize }} \mathrm{t}\right)\right|_{\text {no shortage }}$ & $0.183(0.208)$ & $0.169^{* *}(0.070)$ & $0.074 \quad(0.074)$ \\
\hline $\mathrm{R}^{2}$ & 0.821 & 0.577 & 0.851 \\
\hline no. of observations & 70 & 71 & 102 \\
\hline dependent variable: & $\ln \left(\right.$ gap $^{\text {steak\&bone }} /$ gap $\left.^{\text {maize }}\right)$ & $\ln \left(\right.$ gap $\left.^{\text {steak\&bone }}\right)$ & $\ln \left(\right.$ gap $\left.^{\text {maize }}\right)$ \\
\hline $\ln \left(q^{\text {maize }}{ }_{t-1} / \text { req }^{\text {maize }} t\right)_{\text {|shortage }}$ & $0.264^{* *}(0.119)$ & $0.093^{*}(0.052)$ & $-0.268^{* *}(0.124)$ \\
\hline$\left.\ln \left(\mathrm{q}^{\text {maize }}{ }_{\mathrm{t}-1} / \mathrm{req}^{\text {maize }} \mathrm{t}\right)\right|_{\text {no shortage }}$ & $-0.100 \quad(0.102)$ & $0.013(0.038)$ & $0.074 \quad(0.074)$ \\
\hline $\mathrm{R}^{2}$ & 0.838 & 0.641 & 0.851 \\
\hline no. of observations & 99 & 98 & 102 \\
\hline dependent variable: & $\ln \left(\right.$ gap $^{\text {pork}} /$ gap $\left.^{\text {maize }}\right)$ & $\ln \left(\right.$ gap $\left.^{\text {pork }}\right)$ & $\ln \left(\right.$ gap $\left.^{\text {maize }}\right)$ \\
\hline $\ln \left(q^{\text {maize }}{ }_{t-1} / \text { req }^{\text {maize }}\right)_{\mid \text {shortage }}$ & $0.418^{*}(0.201)$ & $0.112^{*}(0.061)$ & $-0.268^{* *}(0.124)$ \\
\hline $\ln \left(\mathrm{q}^{\text {maize }} \mathrm{t-1} / \mathrm{req}^{\text {maize }} \mathrm{t}\right)_{\text {no shortage }}$ & $-0.103(0.174)$ & $0.078(0.044)$ & $0.074 \quad(0.074)$ \\
\hline $\mathrm{R}^{2}$ & 0.840 & 0.638 & 0.851 \\
\hline no. of observations & 83 & 87 & 102 \\
\hline
\end{tabular}

Table A3b Meat-Maize Price Gaps versus Maize Abundance-Scarcity, 1992-2009, central

\begin{tabular}{|c|c|c|c|}
\hline & (1) & (2) & (3) \\
\hline dependent variable: & $\ln \left(\right.$ gap $^{\text {goat }} /$ gap $\left.^{\text {maize }}\right)$ & $\ln \left(\right.$ gap $\left.^{\text {goat }}\right)$ & $\ln \left(\right.$ gap $\left.^{\text {maize }}\right)$ \\
\hline $\ln \left(q^{\text {maize }}{ }_{t-1} / \text { req }^{\text {maize }}\right)_{\text {|shortage }}$ & $0.018(0.167)$ & $0.036(0.055)$ & $-0.058(0.096)$ \\
\hline$\left.\ln \left(\mathrm{q}^{\text {maize }} \mathrm{t-1} / \mathrm{req}^{\text {maize }} \mathrm{t}\right)\right|_{\text {no shortage }}$ & $0.003(0.135)$ & $-0.019(0.041)$ & $-0.032(0.130)$ \\
\hline $\mathrm{R}^{2}$ & 0.873 & 0.444 & 0.844 \\
\hline no. of observations & 160 & 173 & 202 \\
\hline dependent variable: & $\ln \left(\right.$ gap $^{\text {steak\&bone }} /$ gap $\left.^{\text {maize }}\right)$ & $\ln \left(\right.$ gap $\left.^{\text {steak\&bone }}\right)$ & $\ln \left(\right.$ gap $\left.^{\text {maize }}\right)$ \\
\hline 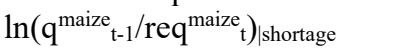 & $0.129(0.123)$ & $-0.021(0.030)$ & $-0.058(0.096)$ \\
\hline $\ln \left(\mathrm{q}^{\text {maize }}{ }_{\mathrm{t}-1} / \mathrm{req}^{\text {maize }} \mathrm{t}\right)$ |no shortage & $0.037(0.138)$ & $-0.044(0.035)$ & $-0.032(0.130)$ \\
\hline $\mathrm{R}^{2}$ & 0.838 & 0.570 & 0.844 \\
\hline no. of observations & 181 & 197 & 202 \\
\hline dependent variable: & $\ln \left(\right.$ gap $^{\text {pork}} /$ gap $\left.^{\text {maize }}\right)$ & $\ln \left(\right.$ gap $\left.^{\text {pork }}\right)$ & $\ln \left(\right.$ gap $\left.^{\text {maize }}\right)$ \\
\hline $\ln \left(q^{\text {maize }}{ }_{t-1} / \text { req }^{\text {maize }} t\right)_{\text {|shortage }}$ & $-0.061(0.152)$ & $0.014(0.051)$ & $-0.058(0.096)$ \\
\hline $\ln \left(\mathrm{q}^{\text {maize }}{ }_{\mathrm{t}-1} / \mathrm{req}^{\text {maize }} \mathrm{t}\right)$ |no shortage & $-0.071(0.177)$ & $-0.051(0.041)$ & $-0.032(0.130)$ \\
\hline $\mathrm{R}^{2}$ & 0.855 & 0.447 & 0.844 \\
\hline no. of observations & 167 & 177 & 202 \\
\hline
\end{tabular}


Table A3c Meat-Maize Price Gaps versus Maize Abundance-Scarcity, 1992-2009, south

\begin{tabular}{|c|c|c|c|}
\hline & (1) & (2) & (3) \\
\hline dependent variable: & $\ln \left(\right.$ gap $^{\text {goat }} /$ gap $\left.^{\text {maize }}\right)$ & $\ln \left(\right.$ gap $\left.^{\text {goat }}\right)$ & $\ln \left(\right.$ gap $\left.^{\text {maize }}\right)$ \\
\hline 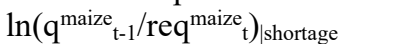 & $0.263^{* * *}(0.086)$ & $0.033^{* *}(0.015)$ & $-0.198^{* * *}(0.060)$ \\
\hline $\ln \left(\mathrm{q}^{\text {maize }} \mathrm{t}-1 / \mathrm{req}^{\text {maize }} \mathrm{t}\right) \mid$ no shortage & $-0.014 \quad(0.166)$ & $0.064(0.046)$ & $0.040 \quad(0.110)$ \\
\hline $\mathrm{R}^{2}$ & 0.825 & 0.644 & 0.796 \\
\hline no. of observations & 146 & 171 & 172 \\
\hline dependent variable: & $\ln \left(\right.$ gap $^{\text {steak\&bone }} /$ gap $\left.^{\text {maize }}\right)$ & $\ln \left(\right.$ gap $\left.^{\text {steak\&bone }}\right)$ & $\ln \left(\right.$ gap $\left.^{\text {maize }}\right)$ \\
\hline $\ln \left(q^{\text {maize }}{ }_{t-1} / \text { req }^{\text {maize }}{ }_{t}\right)_{\text {shortage }}$ & $0.292^{* * *}(0.084)$ & $0.027^{* *}(0.010)$ & $-0.198^{* * *}(0.060)$ \\
\hline $\ln \left(\mathrm{q}^{\text {maize }} \mathrm{t-1} / \mathrm{req}^{\text {maize }} \mathrm{t}\right) \mid$ no shortage & $-0.061 \quad(0.133)$ & $-0.052 \quad(0.042)$ & $0.040 \quad(0.110)$ \\
\hline $\mathrm{R}^{2}$ & 0.851 & 0.636 & 0.796 \\
\hline no. of observations & 133 & 164 & 172 \\
\hline dependent variable: & $\ln \left(\right.$ gap $^{\text {pork }} /$ gap $\left.^{\text {maize }}\right)$ & $\ln \left(\right.$ gap $\left.^{\text {pork }}\right)$ & $\ln \left(\right.$ gap $\left.^{\text {maize }}\right)$ \\
\hline $\left.\ln \left(\mathrm{q}^{\text {maize }}{ }_{\mathrm{t}-1} / \mathrm{req}^{\text {maize }} \mathrm{t}\right)\right)_{\text {shortage }}$ & $0.279^{* *}(0.131)$ & $0.040^{*}(0.020)$ & $-0.198^{* * *}(0.060)$ \\
\hline $\ln \left(\mathrm{q}^{\text {maize }} \mathrm{t-1} / \mathrm{req}_{\mathrm{taze}}\right){ }_{\mid \text {no shortage }}$ & $0.081 \quad(0.218)$ & $0.023(0.087)$ & $0.040 \quad(0.110)$ \\
\hline $\mathrm{R}^{2}$ & 0.911 & 0.608 & 0.796 \\
\hline no. of observations & 101 & 112 & 172 \\
\hline
\end{tabular}

Note: Price gaps are calculated as the average price in January, February and March in a specific year (the lean season prices), relative to the average price of the lowest three prices from May to November of the previous year, for a specific market. The source data are monthly market price observations for 72 locations (markets, villages and towns), from January 1991 to October 2009, taken from Agro-Economic Survey, Ministry of Agriculture and Food Security, Government of Malawi (see data section for further details). Equations are estimated with OLS. All estimations include location (market) and time (year) fixed effects. Standard errors clustered by market are reported in brackets below the coefficient. ${ }^{*} p<0.10,{ }^{* *} p<0.05,{ }^{* * *} p<0.01$. 
Table A4a Meat-Maize Price Gaps versus Maize Abundance-Scarcity, 1992-2009, rural

\begin{tabular}{|c|c|c|c|}
\hline & (1) & (2) & (3) \\
\hline dependent variable: & $\ln \left(\right.$ gap $^{\text {goat }} /$ gap $\left.^{\text {maize }}\right)$ & $\ln \left(\right.$ gap $\left.^{\text {goat }}\right)$ & $\ln \left(\right.$ gap $\left.^{\text {maize }}\right)$ \\
\hline $\ln \left(q^{\text {maize }}{ }_{t-1} / \text { req }^{\text {maize }} t\right)_{\text {shortage }}$ & $0.632^{* * *}(0.170)$ & $0.174^{*}(0.083)$ & $-0.281^{* * *}(0.070)$ \\
\hline $\ln \left(q^{\text {maize }}{ }_{t-1} /\right.$ req $\left.^{\text {maize }} t\right) \mid$ no shortage & $(0.369)$ & $0.017(0.067)$ & $(0.203)$ \\
\hline $\mathrm{R}^{2}$ & 0.799 & 0.497 & 0.724 \\
\hline no. of observations & 75 & 78 & 98 \\
\hline dependent variable: & $\ln \left(\right.$ gap $^{\text {steak\&bone }} /$ gap $\left.^{\text {maize }}\right)$ & $\ln \left(\right.$ gap $\left.^{\text {steak\&bone }}\right)$ & $\ln \left(\right.$ gap $\left.^{\text {maize }}\right)$ \\
\hline $\ln \left(q^{\text {maize }}{ }_{t-1} / \text { req }^{\text {maize }} t\right)_{\text {shortage }}$ & $0.321^{* *}(0.145)$ & $0.107^{*}(0.054)$ & $-0.280^{* *}(0.118)$ \\
\hline $\ln \left(\mathrm{q}^{\text {maize }}{ }_{\mathrm{t}-1} / \mathrm{req}^{\text {maize }} \mathrm{t}\right) \mid$ no shortage & $0.177 \quad(0.197)$ & $0.110^{*}(0.051)$ & $-0.099 \quad(0.177)$ \\
\hline $\mathrm{R}^{2}$ & 0.767 & 0.660 & 0.741 \\
\hline no. of observations & 95 & 95 & 113 \\
\hline dependent variable: & $\ln \left(\right.$ gap $^{\text {pork}} /$ gap $\left.^{\text {maize }}\right)$ & $\ln \left(\right.$ gap $\left.^{\text {pork }}\right)$ & $\ln \left(\right.$ gap $\left.^{\text {maize }}\right)$ \\
\hline $\ln \left(\mathrm{q}^{\text {maize }}{ }_{\mathrm{t}-1} / \mathrm{req}^{\text {maize }}\right)_{\text {|shortage }}$ & $0.423^{* * *}(0.146)$ & $0.130^{* *}(0.062)$ & $-0.199^{* *}(0.093)$ \\
\hline $\ln \left(\mathrm{q}^{\text {maize }} \mathrm{t-1} / \mathrm{req}^{\text {maize }} \mathrm{t}\right)$ |no shortage & $0.158 \quad(0.180)$ & $0.081 \quad(0.055)$ & $-0.075 \quad(0121)$ \\
\hline $\mathrm{R}^{2}$ & 0.780 & 0.445 & 0.734 \\
\hline no. of observations & 123 & 135 & 178 \\
\hline
\end{tabular}

Table A4b Meat-Maize Price Gaps versus Maize Abundance-Scarcity, 1992-2009, urban

\begin{tabular}{|c|c|c|c|}
\hline dependent variable: & $\begin{array}{c}(1) \\
\ln \left(\text { gap }^{\text {goat/ }} \text { gap }^{\text {maize }}\right)\end{array}$ & $\begin{array}{c}(2) \\
\ln \left(\text { gap }^{\text {goat }}\right)\end{array}$ & $\begin{array}{c}(3) \\
\ln \left(\text { gap }^{\text {maize }}\right)\end{array}$ \\
\hline 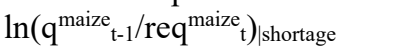 & $0.250(0.181)$ & $0.017(0.025)$ & $-0.045(0.134)$ \\
\hline 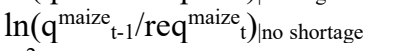 & $0.138(0.170)$ & $0.130(0.109)$ & $-0.132(0.163)$ \\
\hline $\mathrm{R}^{2}$ & 0.907 & 0.561 & 0.890 \\
\hline no. of observations & 114 & 128 & 144 \\
\hline dependent variable: & $\ln \left(\right.$ gap $^{\text {steak\&bone }} /$ gap $\left.^{\text {maize }}\right)$ & $\ln \left(\right.$ gap $\left.^{\text {steak\&bone }}\right)$ & $\ln \left(\right.$ gap $\left.^{\text {maize }}\right)$ \\
\hline 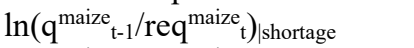 & $0.111(0.099)$ & $0.029(0.018)$ & $-0.045(0.134)$ \\
\hline $\ln \left(\mathrm{q}^{\text {maize }} \mathrm{t-1} /\left.\mathrm{req}^{\text {maize }}{ }_{\mathrm{t}}\right|_{\text {no shortage }}\right.$ & $0.102(0.191)$ & $0.038(0.096)$ & $-0.132(0.163)$ \\
\hline $\mathrm{R}^{2}$ & 0.875 & 0.541 & 0.890 \\
\hline no. of observations & 134 & 153 & 144 \\
\hline dependent variable: & $\ln \left(\right.$ gap $^{\text {pork}} /$ gap $\left.^{\text {maize }}\right)$ & $\ln \left(\right.$ gap $\left.^{\text {pork }}\right)$ & $\ln \left(\right.$ gap $\left.^{\text {maize }}\right)$ \\
\hline $\ln \left(q^{\text {maize }}{ }_{t-1} / \text { req }^{\text {maize }}\right)_{\mid \text {shortage }}$ & $0.110(0.171)$ & $0.072^{* *}(0.029)$ & $-0.045(0.134)$ \\
\hline$\left.\ln \left(\mathrm{q}^{\text {maize }}{ }_{\mathrm{t}-1} / \mathrm{req}^{\text {maize }}{ }_{\mathrm{t}}\right)\right|_{\text {no shortage }}$ & $0.203(0.230)$ & $0.126 \quad(0.085)$ & $-0.132(0.163)$ \\
\hline $\mathrm{R}^{2}$ & 0.907 & 0.586 & 0.890 \\
\hline no. of observations & 115 & 120 & 144 \\
\hline
\end{tabular}

Note: Price gaps are calculated as the average price in January, February and March in a specific year (the lean season prices), relative to the average price of the lowest three prices from May to November of the previous year, for a specific market. The source data are monthly market price observations for 72 locations (markets, villages and towns), from January 1991 to October 2009, taken from Agro-Economic Survey, Ministry of Agriculture and Food Security, Government of Malawi (see data section for further details). Rural and urban markets are identified by the minimum distance to a city (either Lilongwe, Blantyre, Mzuzu or Zomba): rural markets are markets in the districts Chitipa, Karonga, Nsanje, Mzimba, Kasungu and Mangochi; urban markets are markets in the districts Lilongwe, Blantyre, Zomba, Dowa, Dedza and Mulanje. Equations are estimated with OLS. All estimations include location (market) and time (year) fixed effects. Standard errors clustered by market are reported in brackets below the coefficient. ${ }^{*} p<0.10$, ${ }^{* *} p<0.05,{ }^{* * *} p<0.01$. 


\section{Two-way fixed effects}

Table A5 Meat-Maize Gaps versus Maize Abundance-Scarcity (TWFE), 1992-2009

\begin{tabular}{|c|c|c|c|}
\hline & (1) & (2) & (3) \\
\hline dependent variable: & $\ln \left(\right.$ gap $^{\text {goat }} /$ gap $\left.^{\text {maize }}\right)$ & $\ln \left(\right.$ gap $\left.^{\text {goat }}\right)$ & $\ln \left(\right.$ gap $\left.^{\text {maize }}\right)$ \\
\hline $\ln \left(q^{\text {maize }}{ }_{t-1} /\right.$ req $\left.^{\text {maize }} t\right){ }_{\mid \text {shortage }}$ & $0.364^{* * *}(0.085)$ & $0.030^{*}(0.016)$ & $-0.193^{* * *}(0.053)$ \\
\hline $\ln \left(\mathrm{q}^{\text {maize }}{ }_{\mathrm{t}-1} / \mathrm{req}^{\text {maize }} \mathrm{t}\right){ }_{\mid \text {no shortage }}$ & $-0.061 \quad(0.107)$ & $0.033(0.020)$ & $0.039 \quad(0.085)$ \\
\hline $\mathrm{R}^{2}$ within & 0.063 & 0.049 & 0.0332 \\
\hline between & 0.048 & 0.0078 & 0.1111 \\
\hline overall & 0.037 & 0.0082 & 0.0144 \\
\hline no. of observations / groups & $390 / 68$ & $422 / 69$ & $493 / 70$ \\
\hline dependent variable: & $\ln \left(\right.$ gap $^{\text {steak\&bone }} /$ gap $\left.^{\text {maize }}\right)$ & $\ln \left(\right.$ gap $\left.^{\text {steak\&bone }}\right)$ & $\ln \left(\right.$ gap $\left.^{\text {maize }}\right)$ \\
\hline $\ln \left(q^{\text {maize }}{ }_{t-1} /\right.$ req $\left.^{\text {maize }} t\right) \mid$ shortage & $0.223^{* * *}(0.062)$ & $0.015(0.013)$ & $-0.193^{* * *}(0.053)$ \\
\hline $\ln \left(\mathrm{q}^{\text {maize }} \mathrm{t-1} / \mathrm{req}^{\text {maize }} \mathrm{t}\right){ }_{\mid \text {no shortage }}$ & $-0.004 \quad(0.081)$ & $-0.003(0.021)$ & $0.039 \quad(0.085)$ \\
\hline $\mathrm{R}^{2}$ within & 0.038 & 0.0037 & 0.0332 \\
\hline between & 0.016 & 0.0021 & 0.1111 \\
\hline overall & 0.016 & 0.000 & 0.0144 \\
\hline no. of observations / groups & $430 / 68$ & $469 / 70$ & $493 / 70$ \\
\hline dependent variable: & $\ln \left(\right.$ gap $^{\text {pork}} /$ gap $\left.^{\text {maize }}\right)$ & $\ln \left(\right.$ gap $\left.^{\text {pork }}\right)$ & $\ln \left(\right.$ gap $\left.^{\text {maize }}\right)$ \\
\hline $\ln \left(q^{\text {maize }}{ }_{t-1} /\right.$ req $\left.^{\text {maize }} t\right) \mid$ shortage & $0.280^{* * *}(0.085)$ & $0.041^{*}(0.024)$ & $-0.193^{* * *}(0.053)$ \\
\hline $\ln \left(\mathrm{q}^{\text {maize }} \mathrm{t-1} / \mathrm{req}^{\text {maize }} \mathrm{t}\right){ }_{\mid \text {no shortage }}$ & $-0.109 \quad(0.109)$ & $-0.011(0.023)$ & $0.039 \quad(0.085)$ \\
\hline $\mathrm{R}^{2}$ within & 0.040 & 0.014 & 0.0332 \\
\hline between & 0.034 & 0.018 & 0.1111 \\
\hline overall & 0.027 & 0.007 & 0.0144 \\
\hline no. of observations / groups & $374 / 66$ & $389 / 67$ & $493 / 70$ \\
\hline
\end{tabular}

Note: Price gaps are calculated as the average price in January, February and March in a specific year (the lean season prices), relative to the average price of the lowest three prices from May to November of the previous year, for a specific market. The source data are monthly market price observations for 72 locations (markets, villages and towns), from January 1991 to October 2009, taken from Agro-Economic Survey, Ministry of Agriculture and Food Security, Government of Malawi (see data section for further details). Equations are estimated with Fixed Effects (market and year). Standard errors clustered by market are reported in brackets below the coefficient. ${ }^{*} p<0.10,{ }^{* *} p<0.05$, ${ }^{* * *} p<0.01$ 


\section{Driscoll-Kraay standard errors}

Table A6 Meat-Maize Gaps versus Maize Abundance-Scarcity, FE with Driscoll-Kraay Standard Errors, 1992 - 2009

\begin{tabular}{|c|c|c|c|}
\hline & (1) & (2) & (3) \\
\hline dependent variable: & $\ln \left(\right.$ gap $^{\text {goat }} /$ gap $\left.^{\text {maize }}\right)$ & $\ln \left(\right.$ gap $\left.^{\text {goat }}\right)$ & $\ln \left(\right.$ gap $\left.^{\text {maize }}\right)$ \\
\hline $\ln \left(q^{\text {maize }}{ }_{t-1} /\right.$ req $\left.^{\text {maize }} t\right) \mid$ shortage & $0.263^{* * *}(0.086)$ & $0.034^{* *}(0.013)$ & $-0.170^{* *}(0.059)$ \\
\hline $\ln \left(\mathrm{q}^{\text {maize }}{ }_{\mathrm{t}-1} / \mathrm{req}^{\text {maize }} \mathrm{t}\right) \mid$ no shortage & $0.086 \quad(0.083)$ & $0.034 \quad(0.024)$ & $-0.053 \quad(0.047)$ \\
\hline within $\mathrm{R}^{2}$ & 0.782 & 0.349 & 0.765 \\
\hline no. of observations & 376 & 415 & 478 \\
\hline dependent variable: & $\ln \left(\right.$ gap $^{\text {steak\&bone }} /$ gap $\left.^{\text {maize }}\right)$ & $\ln \left(\right.$ gap $\left.^{\text {steak\&bone }}\right)$ & $\ln \left(\right.$ gap $\left.^{\text {maize }}\right)$ \\
\hline $\ln \left(q^{\text {maize }}{ }_{t-1} / \mathrm{req}^{\text {maize }}\right)_{\mid \text {shortage }}$ & $0.195^{* * *}(0.053)$ & $0.032^{* * *}(0.008)$ & $-0.170^{* *}(0.059)$ \\
\hline $\ln \left(\mathrm{q}^{\text {maize }}{ }_{\mathrm{t}-1} / \mathrm{req}^{\text {maize }} \mathrm{t}\right) \mid$ no shortage & $0.047 \quad(0.044)$ & $-0.012 \quad(0.014)$ & $-0.053 \quad(0.047)$ \\
\hline within $\mathrm{R}^{2}$ & 0.773 & 0.442 & 0.765 \\
\hline no. of observations & 415 & 463 & 478 \\
\hline dependent variable: & $\ln \left(\right.$ gap $^{\text {pork}} /$ gap $\left.^{\text {maize }}\right)$ & $\ln \left(\right.$ gapp $\left.^{\text {pork }}\right)$ & $\ln \left(\right.$ gap $\left.^{\text {maize }}\right)$ \\
\hline 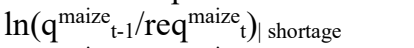 & $0.181^{* * *}(0.034)$ & $0.059^{* * *}(0.017)$ & $-0.170^{* *}(0.059)$ \\
\hline 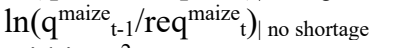 & $0.051 \quad(0.069)$ & $0.000 \quad(0.014)$ & $-0.053 \quad(0.047)$ \\
\hline within $\mathrm{R}^{2}$ & 0.814 & 0.321 & 0.765 \\
\hline no. of observations & 354 & 379 & 478 \\
\hline
\end{tabular}

Note: Price gaps are calculated as the average price in January, February and March in a specific year (the lean season prices), relative to the average price of the lowest three prices from May to November of the previous year, for a specific market. The source data are monthly market price observations for 72 locations (markets, villages and towns), from January 1991 to October 2009, taken from Agro-Economic Survey, Ministry of Agriculture and Food Security, Government of Malawi (see data section for further details). Equations are estimated with market fixed effects and Driscoll-Kraay standard errors. The maximum lag is 2 years. All estimations also include year fixed effects. Standard errors clustered by market are reported in brackets below the coefficient. ${ }^{*} p<0.10,{ }^{* *} p<0.05,{ }^{* * *} p<0.01$. 


\section{Instrumental variable estimation}

Strictly there is no need to instrument the abundance-scarcity variable or apply any other adjustment (for omitted variables, reverse causality, endogeneity, etc): production of maize relates to the previous season and is hence predetermined, and population by district develops only gradually over time, without major shifts and shocks, and is also largely predetermined. However, to avoid potential issues on this account between maize prices and maize production (versus maize requirements), we instrument the abundance-scarcity variable with seasonal rainfall by district and rainfall levels (low-medium-high) by ADD.

Hence, we have:

$\operatorname{gap}_{j t}^{x}=\eta_{0}+\eta_{1}$ malze productıon $_{\jmath t-1 / \text { malze requirement }}{ }_{j t}+\varphi_{j}+\psi_{t}+\varepsilon_{j t}$,

and

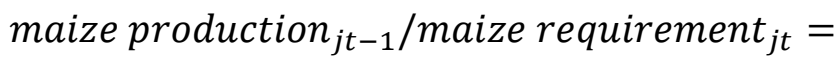

$$
\theta_{0}+\theta_{1} \text { seasonal rainfall }_{j t}+\sum \theta_{2, k m} \text { rainfall level }_{t k} * A D D_{m}
$$

Equation (5) is estimated to address potential biases due to endogeneity and estimation results are reported in the table below. 
Table A7 Meat-Maize Gaps versus Maize Abundance-Scarcity (IV-2SLS), 1992-2009

\begin{tabular}{|c|c|c|c|}
\hline & (1) & (2) & (3) \\
\hline dependent variable: & $\ln \left(\right.$ gap $^{\text {goat }} /$ gap $\left.^{\text {maize }}\right)$ & $\ln \left(\right.$ gap $\left.^{\text {goat }}\right)$ & $\ln \left(\right.$ gap $\left.^{\text {maize }}\right)$ \\
\hline $\ln \left(q^{\text {maize }}{ }_{t-1} /\right.$ req $\left._{t}^{\text {maize }}\right)$ & $0.294^{*}(0.155)$ & $0.084^{*}(0.043)$ & $-0.159^{*}(0.091)$ \\
\hline $\mathrm{F}() ;($ Prob $>\mathrm{F})$ & $2.76(0.1013)$ & $2.95(0.0905)$ & $2.46(0.1211)$ \\
\hline Kleibergen-Paap rk LM statistic & 31.673 & 31.870 & 32.750 \\
\hline Cragg-Donald Wald F statistic & 2.041 & 3.409 & 2.665 \\
\hline Kleibergen-Paap rk Wald F statistic & 9.264 & 12.539 & 12.596 \\
\hline Hansen J statistic & 16.659 & 14.715 & 14.304 \\
\hline no. of observations & 378 & 409 & 484 \\
\hline dependent variable: & $\ln \left(\right.$ gap $^{\text {steak\&bone }} /$ gap $\left.^{\text {maiz }}\right)$ & $\ln \left(\right.$ gap $\left.^{\text {steak\&bone }}\right)$ & $\ln \left(\right.$ gap $\left.^{\text {maize }}\right)$ \\
\hline $\ln \left(q^{\text {maize }}{ }_{t-1} / \mathrm{req}^{\text {maize }} t\right)$ & $0.220^{* *}(0.100)$ & $0.069^{* *}(0.030)$ & $-0.159^{*}(0.091)$ \\
\hline $\mathrm{F}() ;($ Prob $>$ F $)$ & $3.80(0.0554)$ & $4.3(0.0418)$ & $2.46(0.1211)$ \\
\hline Kleibergen-Paap rk LM statistic & 25.835 & 24.066 & 32.750 \\
\hline Cragg-Donald Wald F statistic & 1.732 & 2.408 & 2.665 \\
\hline Kleibergen-Paap rk Wald F statistic & 18.973 & 22.273 & 12.596 \\
\hline Hansen $\mathrm{J}$ statistic & 12.018 & 16.185 & 14.304 \\
\hline no. of observations & 416 & 460 & 484 \\
\hline dependent variable: & $\ln \left(\right.$ gap $^{\text {pork}} /$ gap $\left.^{\text {maize }}\right)$ & $\ln \left(\right.$ gapp $\left.^{\text {pork }}\right)$ & $\ln \left(\right.$ gap $\left.^{\text {maize }}\right)$ \\
\hline $\ln \left(\mathrm{q}_{\mathrm{t}-1}^{\text {maize }} / \mathrm{req}_{\mathrm{t}}^{\text {maize }}\right)$ & $0.197^{* *}(0.098)$ & $0.084^{*}(0.049)$ & $-0.159^{*}(0.091)$ \\
\hline $\mathrm{F}() ;.($ Prob > F $)$ & $3.05(0.0856)$ & $2.20(0.1424)$ & $2.46(0.1211)$ \\
\hline Kleibergen-Paap rk LM statistic & 31.493 & 33.705 & 32.750 \\
\hline Cragg-Donald Wald F statistic & 2.916 & 2.943 & 2.665 \\
\hline Kleibergen-Paap rk Wald F statistic & 18.290 & 17.035 & 12.596 \\
\hline Hansen J statistic & 11.880 & 19.170 & 14.304 \\
\hline no. of observations & 358 & 380 & 484 \\
\hline
\end{tabular}

Note: Price gaps are calculated as the average price in January, February and March in a specific year (the lean season prices), relative to the average price of the lowest three prices from May to November of the previous year, for a specific market. The source data are monthly market price observations for 72 locations (markets, villages and towns), from January 1991 to October 2009, taken from Agro-Economic Survey, Ministry of Agriculture and Food Security, Government of Malawi (see data section for further details). Equations are estimated with IV-2SLS. Instruments for the abundance-scarcity variable are last season rainfall by district and rainfall by indicator (low-medium-high) interacted with ADD. All estimations include location (market) and time fixed effects. Standard errors clustered by market are reported in brackets below the coefficient. ${ }^{*} p<0.10,{ }^{* *} p<0.05,{ }^{* * *} p<0.01$. Kleibergen-Paap rk LM statistic: under-identification test; Cragg-Donald Wald F statistic and Kleibergen-Paap rk Wald F statistic: weak identification test; Hansen J statistic: over-identification test of all instruments. 


\section{Spatial spillovers}

Table A8 Meat-Maize Gaps versus Maize Abundance-Scarcity, fixed effect spatial regression, 1992-2009

\begin{tabular}{|c|c|c|c|}
\hline dependent variable: & $\begin{array}{c}(1) \\
\ln \left(\text { gap }^{\mathrm{gt}} / \text { gap }^{\mathrm{mz}}\right)\end{array}$ & $\begin{array}{c}(2) \\
\ln \left(\text { gap }^{\mathrm{gt}}\right)\end{array}$ & $\begin{array}{c}(3) \\
\ln \left(\text { gap }^{\mathrm{mz}}\right)\end{array}$ \\
\hline \multicolumn{4}{|l|}{$\ln \left(\operatorname{gap}^{x} / \operatorname{gap}^{x}\right)$} \\
\hline $\ln \left(q^{\text {maize }} t-1 /\right.$ req $\left.^{\text {maize }} t\right)$ |no shortage & $0.160 \quad(0.107)$ & $0.045^{*}(0.025)$ & $-0.054(0.085)$ \\
\hline $\ln \left(\mathrm{q}^{\text {maize }} \mathrm{t-1} / \mathrm{req}_{\mathrm{taize}}\right){ }_{\text {shortage }}$ & $0.381^{* * *}(0.092)$ & $0.041^{* *}(0.017)$ & $-0.083(0.060)$ \\
\hline \multicolumn{4}{|l|}{ Inverse Distance Weight } \\
\hline$\left.\ln \left(\mathrm{q}_{\mathrm{t}-1}^{\text {maize }} / \mathrm{req}_{\mathrm{taize}}^{\mathrm{ma}}\right)\right|_{\text {no shortage }}$ & $-1.126^{* *}(0.448)$ & $-0.179^{* * *}(0.064)$ & $0.428^{* *}(0.214)$ \\
\hline $\ln \left(\mathrm{q}^{\text {maize }}{ }_{\mathrm{t}-1} / \mathrm{req}^{\text {maize }}\right)_{\text {shortage }}$ & $-0.381 \quad(0.398)$ & $0.006 \quad(0.032)$ & $-0.417^{* * *}(0.092)$ \\
\hline $\ln \left(\operatorname{gap}^{\mathrm{x}} / \operatorname{gap}^{\mathrm{x}}\right)$ & $0.403^{* *}(0.171)$ & $-0.058 \quad(0.218)$ & $0.344^{*}(0.184)$ \\
\hline Error & $0.348^{*}(0.189)$ & $-0.199 \quad(0.266)$ & $0.404^{* *}(0.190)$ \\
\hline Standard deviation of errors & $0.219(0.013)$ & $0.050(0.003)$ & $0.175(0.009)$ \\
\hline Wald chi2 (5); (Prob > chi2) & $27.92(0.0000)$ & $15.35(0.0090)$ & $43.79(0.0000)$ \\
\hline pseudo $\mathrm{R}^{2}$ & 0.0248 & 0.0084 & 0.0297 \\
\hline Wald test of spatial terms: chi2 (4); (Prob > chi2) & $37.27(0.0000)$ & $11.87(0.0183)$ & $106.2(0.0000)$ \\
\hline no. of observations / no of groups & $170 / 17$ & $170 / 17$ & $196 / 14$ \\
\hline dependent variable: & $\ln \left(\right.$ gap $^{\text {sb }} /$ gap $\left.^{\mathrm{mz}}\right)$ & $\ln \left(\right.$ gap $\left.^{\text {sb }}\right)$ & $\ln \left(\right.$ gap $\left.^{\mathrm{mz}}\right)$ \\
\hline \multicolumn{4}{|l|}{$\ln \left(\operatorname{gap}^{x} / \operatorname{gap}^{x}\right)$} \\
\hline $\left.\ln \left(\mathrm{q}^{\text {maize }} \mathrm{t-1} / \mathrm{req}_{\mathrm{taize}}\right)\right)_{\text {no shortage }}$ & $0.020 \quad(0.077)$ & $0.018 \quad(0.021)$ & $-0.054(0.085)$ \\
\hline $\ln \left(\mathrm{q}^{\text {maize }}{ }_{\mathrm{t}-1} / \mathrm{req}_{\mathrm{t}}^{\text {maize }}\right)_{\text {|shortage }}$ & $0.262^{* * *}(0.064)$ & $0.044^{* * *}(0.015)$ & $-0.083(0.060)$ \\
\hline \multicolumn{4}{|l|}{ Inverse Distance Weight } \\
\hline $\ln \left(q^{\text {maize }} t-1 /\right.$ req $\left.^{\text {maize }} t\right){ }_{\text {|no shortage }}$ & $-0.374^{*}$ & $-0.056(0.193)$ & $0.428^{* *}(0.214)$ \\
\hline $\left.\ln \left(\mathrm{q}^{\text {maize }}{ }_{\mathrm{t}-1} / \mathrm{req}_{\mathrm{t}}^{\text {maize }}\right)\right)_{\text {shortage }}$ & $0.351^{* * *}(0.130)$ & $-0.023(0.022)$ & $-0.417^{* * *}(0.092)$ \\
\hline $\ln \left(\right.$ gap $^{x} /$ gap $\left.^{x}\right)$ & $0.360^{* *} \quad(0.163)$ & $-0.223(0.214)$ & $0.344^{*}(0.184)$ \\
\hline Error & $0.379^{* *} \quad(0.175)$ & $-0.227(0.214)$ & $0.404^{* *}(0.190)$ \\
\hline Standard deviation of errors & $0.159(0.008)$ & $0.044(0.002)$ & $0.175(0.009)$ \\
\hline Wald chi2 (5); (Prob > chi2) & $49.99(0.0000)$ & $15.56(0.0082)$ & $43.79(0.0000)$ \\
\hline pseudo $\mathrm{R}^{2}$ & 0.0236 & 0.0188 & 0.0297 \\
\hline Wald test of spatial terms: chi2 (4); (Prob > chi2) & $81.43(0.0000)$ & $8.32(0.0805)$ & $106.2(0.0000)$ \\
\hline no. of observations / no of groups & $240 / 15$ & $198 / 18$ & $196 / 14$ \\
\hline dependent variable: & $\ln \left(\right.$ gap $^{\text {pork}} /$ gap $\left.^{\text {maize }}\right)$ & $\ln \left(\right.$ gap $\left.^{\text {pork }}\right)$ & $\ln \left(\right.$ gap $\left.^{\text {maize }}\right)$ \\
\hline \multicolumn{4}{|l|}{$\ln \left(\operatorname{gap}^{x} / \operatorname{gap}^{x}\right)$} \\
\hline $\ln \left(\mathrm{q}^{\text {maize }}{ }_{\mathrm{t}-1} / \mathrm{req}^{\text {maize }} \mathrm{t}\right) \mid$ no shortage & $(0.118)$ & $(0.021)$ & $-0.054(0.085)$ \\
\hline $\ln \left(\mathrm{q}^{\text {maize }} \mathrm{t-1} / \mathrm{req}_{\mathrm{taize}}\right)_{\text {|shortage }}$ & $0.464^{* * *}(0.098)$ & $0.048^{* *}(0.019)$ & $-0.083(0.060)$ \\
\hline \multicolumn{4}{|l|}{ Inverse Distance Weight } \\
\hline $\ln \left(\mathrm{q}^{\text {maize }} \mathrm{t-1} / \mathrm{req}_{\mathrm{taize}}\right){ }_{\mid \text {no shortage }}$ & $-0.244 \quad(0.338)$ & $-0.030 \quad(0.048)$ & $0.428^{* *} \quad(0.214)$ \\
\hline $\ln \left(\mathrm{q}^{\text {maize }}{ }_{\mathrm{t}-1} / \mathrm{req}^{\text {maize }} \mathrm{t}\right){ }_{\text {shortage }}$ & $0.189(0.533)$ & $0.160^{* * *}(0.055)$ & $-0.417^{* * *}(0.092)$ \\
\hline $\ln \left(\operatorname{gap}^{x} / \operatorname{gap}^{x}\right)$ & $0.338^{*}(0.195)$ & $(0.244)$ & $0.344^{*} \quad(0.184)$ \\
\hline Error & $0.265(0.229)$ & $(0.251)$ & $0.404^{* *}(0.190)$ \\
\hline Standard deviation of errors & $0.223(0.014)$ & $(0.002)$ & $0.175 \quad(0.009)$ \\
\hline Wald chi2 (5); (Prob > chi2) & $26.22(0.0001)$ & $29.49(0.0000)$ & $43.79(0.0000)$ \\
\hline pseudo $\mathrm{R}^{2}$ & 0.0241 & 0.0289 & 0.0297 \\
\hline Wald test of spatial terms: chi2 (4); (Prob > chi2) & $13.95(0.0074)$ & $11.77(0.0192)$ & $106.2(0.0000)$ \\
\hline no. of observations / no of groups & $143 / 13$ & $168 / 14$ & $196 / 14$ \\
\hline
\end{tabular}

Note: Price gaps are calculated as the average price in January, February and March in a specific year (the lean season prices), relative to the average price of the lowest three prices from May to November of the previous year, for a specific market. The source data are monthly market price observations for 72 locations (markets, villages and towns), from January 1991 to October 2009, taken from Agro-Economic Survey, Ministry of Agriculture and Food Security, Government of Malawi (see data section for further details). The fixed effect spatial regression (spxtreress) specifies spatial correlation of the dependent variable, the explanatory variable and the error term. The inverse-distance matrix has zero weights for locations more than $50 \mathrm{~km}$ apart.. Standard errors are reported in brackets next to the coefficient. ${ }^{*} p<0.10,{ }^{* *} p<0.05,{ }^{* * *} p<0.01$. 
